${ }^{3}$ Calcutta, India

\title{
NEW SPECIES AND INTERESTING RECORDS OF ACRIDIDAE (ORTHOPTERA) FROM NORTHEAST INDIA
}

\begin{abstract}
Ingrisch, S., F. Willemse \& M. S. Shishodia, 2004. New species and interesting records of Acrididae (Orthoptera) from Northeast India. - Tijdschrift voor Entomologie 147: 289-320, figs. 1-205. [ISSN 0040-7496]. Published 1 December 2004.

One new genus and ten new species of Acrididae are described from India. The new taxa are in Oxyinae Lemba motinagar sp. n. from Meghalaya, Oxytauchira jaintia sp. n. from Meghalaya, in Copacridinae Eucoptacra abbreviata sp. n. from Manipur, and in Catantopinae Assamacris spinipicta sp. n. from Manipur, Genimen lailad sp. n. from Meghalaya, Genimen amarpur sp. n. from South Tripura, Apalniacris gen. n., Apalniacris jalpaiguri sp. n. from West Bengal, Apalniacris dampha sp. n. from Mizoram, Apalniacris ukhrulsp. n. from Manipur, and Apalniacris shillong sp. $\mathbf{n}$. from Meghalaya. A short-winged variant of Oxya velox (Fabricius, 1787) is reported from Mizoram. A third species of Genimen, probably Genimen yunnanensis Zheng et al., 1988, is reported for the first time from India (Manipur). Types and other voucher specimens are in the collection of the Zoological Survey of India, Calcutta.

Dr. Sigfrid Ingrisch (corresponding author), Eichendorffweg 4, D-34385 Bad Karlshafen, Germany. E-mail: sigfrid.ingrisch@planet-interkom.de

Dr. Fer Willemse, Laurastraat 67, Eygelshoven 6471 JH, The Netherlands. E-mail: fer. willemse@worldonline.nl

Dr. Mahendra S. Shishodia, Zoological Survey of India, M-Block, New Alipore, Calcutta 700053, India

Key words. - Orthoptera, Acrididae, India, new genus, new species, description.
\end{abstract}

While the work of Kirby (1914) was the standardwork for the Indian grasshopper fauna (Acridoidea) for a long time, there are now several modern publications dealing with taxonomy, distribution and ecology of the grasshoppers of India (e.g. Bhowmik 1985, 1986, 1993, Tandon 1976, 1988, and numerous papers dealing with single taxa or local areas). The grasshoppers of economic importance are best studied (Mondal et al. 1999). For northeast India, there exist faunal lists (e.g. Bhowmik et al. 1990, Hazra et al. 1995, the latter with key to species), based on investigations by the Zoological Survey of India during several research projects.

The present paper deals with a small but quite interesting collection of specimens found in northeast India by research projects of the Zoological Survey of India during the last decades. Those specimens could not be identified initially, suggesting that they represent new taxa. Further examination was required and this proved to be worth while. Apart from some interesting new systematic and faunistic data, out of 24 studied specimens, one genus and ten species proved to be new.

\section{MATERIAL AND METHODS}

Pencil drawings were prepared under a camera lucida attached to a WILD M5, scanned into a computer and processed to vector graphics using an image processing program.

Descriptions of phallic complexes follows the terminologies used in Dirsh (1956) and Eades (1961). Probably resulting from prior examinations, unfortunately the phallic complex of two specimens was missing.

Measurements are all given in $\mathrm{mm}$.

All material is deposited in the museum of the $\mathrm{Zo}-$ ological Survey of India, Calcutta (ZSI). 


\section{DESCRIPTIONS}

\section{Oxyinae}

Lemba motinagar sp. n. (figs. 1-21)

Type material. - Holotype ô: Meghalaya, Shillong, Motinagar, 21.xi.1974, R. S. Giri. - Paratype 1: Meghalaya, Motinagar forest, Tripura Castle, 12.xi.1980, M. S. Jyrwa.

\section{Description}

Face conical; anterior margin in profile straight (male) or slightly concave (female). Fastigium verticis short, rounded, separated from vertex by a shallow depression. Frontal ridge distinct but subobsolete at clypeo-frontal suture. Index interocular distance : eye length 0.33 (male) or 0.39 (female); one eye $2.5 \times$ (male) or $2.0 \times$ (female) longer than subocular furrow. Pronotum rugose; disc with lateral angles rounded into lateral lobes; median carina hardly indicated; disc cut by three transverse sulci, plus a first transverse sulcus restricted to lateral lobes; posterior margin obtusely angularly excised. Prosternal process slightly compressed, conical, apex acute (figs. 4, 12). Mesosternal lobes broader than long; mesosternal interspace longer than wide; metasternal lobes contiguous (male, fig. 1) or very narrowly separated (female, fig.11). Squamipterous; tegmina covering tympana. Hindfemur moderately slender; dorsal carina smooth and terminating in a small spine; ventral genicular lobes terminating in a spine. Hindtibia with dorsal margin angularly rounded, with 8 external and 10 internal spines at dorsal margins; apical spine present at both sides.

Male genitalia. - Tenth abdominal tergite with furculae (fig. 3). Supra-anal plate with lateral margins almost parallel in basal two thirds, apical third obtusely angular with central area a little projecting; with a median furrow in basal half. Cerci conical, little compressed. Subgenital plate very long, conical; apex terminating into two obtuse tubercles (figs. 2, 3). Epiphallus divided; lophi large, triangular, projecting in a $90^{\circ}$ angle from bridge; another obtuse swelling mediad of lophi; ancorae small, conical (figs. 8-10). Dorsal and ventral aedeagal valves forming large elongate plates directed dorso-apicad (figs. 5-7).

Female genitalia. - Supra-anal plate divided by a strong transverse fold in about middle of length; basal area with disc almost angularly separated from lateral areas; apical area flattened (fig. 14). Cerci conical. Subgenital plate with apex broadly rounded (fig. 13). Ovipositor short; apex of dorsal and ventral valves with margins serrulate and apices hooked (fig. 15).

Coloration. - Yellowish brown (? partly green when alive). Frons concolorous; genae with a small brown stroke below eyes; with a dark brown postocular band, continued on dorsal area of lateral lobes, tegmina and lateral areas of abdominal tergites. Vertex, disc of pronotum and dorsal area of tergites light to medium brown, on vertex and pronotum bordered by light bands. Hindfemur yellowish brown (? green when alive), apical area orange; hind knees blackish brown.

Measurements. - Body ô 15, $q 13$; pronotum ô 3, † 3.8; tegmen ô 2.3, ㅇ 2.8; hindfemur ôे 9 , ㅇ 10 ; fastigium verticis in front of eyes 0.4 , +90.5 ; interocular distance ô 0.7 , ㅇ 0.9 ; eye length ot 2.0 , 92.3 .

\section{Discussion}

The genus Lemba was introduced by Huang (1983). It currently includes four species. It is closely related to Caryanda Stål, 1878. The main difference is the prolonged subgenital plate of the male. The male of the new species differs from L. bituberculata Yin \& Liu, 1987, L. daguanensis Huang, 1983, L. sichuanensis Ma et al., 1994, and L. viriditibia Niu \& Zheng, 1992 by the bifurcate apex of the subgenital plate and from all these except $L$. sichuanensis by the wider mesosternal interspace. In L. yunnana Ma \& Zheng, 1994, the apex of the subgenital plate is also bifurcate, but the apices are flattened and curved laterad and not conical and pointing dorso-apicad as in the new species. Moreover, the mesosternal interspace is very narrow with the lobes almost touching in L. yunnana. From the two species of which the phallic complex is described ( $L$. sichuanensis and $L$. bituberculata), $L$. motinagar also differs by details of the epiphallus and the aedeagal valves.

\section{Etymology}

Named after its area of distribution, the forest of Motinagar (a noun in apposition).

\section{Oxya velox (Fabricius, 1787)}

(figs. 28-42)

Material studied. - 10ิ, Mizoram, Bethil, 12.xii. 1993, R. S. Barman; 1으, Mizoram, Khawzawl, 11. xii.1993, R.S. Barman.

\section{Description}

Integument finely pitted and shining. Antenna with 23 segments (male). Pronotum with disc flattened; anterior margin faintly concave (male) or truncate (female); posterior margin obtusely angular; median carina indicated, cut by three transverse sulci; lateral angles of disc angularly rounded. Brachypterous; tegmina not fully covering abdomen and not reaching hind knees. Last three abdominal sternites and subgenital plate of male with tufts of long hairs (in female smooth, possibly broken). Hindfemur with dorsal carina smooth, terminating in a spinule; hind knees with ventral lobe spiniform.

Male genitalia. - Tenth abdominal tergite entire, 
apical margin faintly excised in middle. Supra-anal plate with a transverse fold; median area in basal half elevated and with a shallow furrow; apex with an obtuse flap (fig. 34). Cerci conical, simple, apex subacute (fig. 33). Epiphallus with narrow bridge; without ancorae; with large hook-like outer lophi and compressed, platelike inner lophi (figs. 35, 37, 38). Ventral aedeagal valves very large, upcurved and rolled almost into a cylinder; apex smooth and brown; dorsal aedeagal valves long, slender, upcurved and almost completely enclosed by ventral aedeagal valves (fig. 36).

Female genitalia. - Tegmen without spinules at anterior margin. Ovipositor valves with tooth-like spines; posterior ventral basivalvular sclerite without spines on inner ventral margin (fig. 42). Subgenital plate as figured in Hollis (1971) for O. velox (fig. 41).

Measurements. - Body ot 23, o 24 ; pronotum ơ 5.0, ㅇ 6.0; tegmen $\widehat{\delta}$ 11.0, ㅇ 12.5; hindfemur $\widehat{\delta}$ 14.0, $q$ 17.0; antenna 0 7.5, broken in $q$; fastigium verticis in front of eyes $\delta 0.7, q 0.8$; interocular distance ôे 0.8 , ㅇ 1.2; eye length ôे 2.8 , ㅇ 3.0 .

\section{Discussion}

The latest complete revision of the genus Oxya Serville, 1831, is that by Hollis (1971); the Indian species have been revised by Usmani \& Shafee (1985). The genus contains more than 70 species. The specimens at hand (northeastern India) agree closely with $O$. velox with the following exceptions: the wings are shorter, the aedeagal valves are more strongly curved, and the teeth of the female subgenital plate are more spaced. Hollis (1971) mentions that the female holotype of Heteracris apta Walker, 1870, from Sylhet (Bangladesh) is conspecific with O. velox though of smaller size. If future research proves that populations from northeastern India differ consistently from other populations and the smaller and/or short-winged forms are not just individual variants, as is not uncommon in some Oxya species, the short-winged form may be regarded as a local race which best could be treated as a subspecies of $O$. velox.

\section{Oxytauchira jaintia sp. n.}

(figs. 22-27, 43-50)

Type material. - Holotype $\widehat{0}$ : Meghalaya, Jaintia Hills, Jowai, 21.v.1990, M. S. Shishodia. - Paratype 1 ㅇ: same data.

\section{Description}

Head conical. Face rugose, anterior margin in profile slightly concave. Fastigium verticis semi-ovoid, separated from vertex by a slight depression. Frontal ridge distinct throughout, margins weak below median ocellus. Index interocular distance : eye length 0.3 (male) or 0.36 (female); interocular distance broader than frontal ridge; eye $2.4 \times$ (male) or $2.1 \times$ (female) longer than subocular groove. Antennae longer than head and pronotum together, filiform; segments very faintly compressed in basal area. Pronotum rugose, almost flat, crossed by three transverse sulci; median carina weak, lateral carinae absent. Prosternal spine compressed and slightly widened to apex; apex with lateral angles conically projecting; the bottom of the wide space between cones with a tubercle (fig. 46). Mesosternal lobes broader than long; mesosternal interspace longer than wide; metasternal lobes contiguous (fig. 43). Tegmen not completely covering abdomen and not reaching hind knees; anterior margin with a basal expansion; apical area strongly tapering; apex narrowly rounded; venation unspecialised. Hindfemur moderately slender; dorsal carina smooth and terminating in a small spine; ventral genicular lobes terminating in a spine (fig. 44). Hindtibia moderately expanded, apically with acute dorsal margins; with 8 external and 10 internal spines; external apical spine present.

Male genitalia. - Tenth abdominal tergite with furculae (fig. 45). Supra-anal plate long triangular, medially grooved in basal half, apical half flat, apex subobtuse. Cerci compressed, conical; apex obtusely pointed (fig. 47). Three apical sterna with tufts of long and dense hairs. (Subgenital plate damaged; phallus lacking in specimen studied.)

Female genitalia. - Supra-anal plate long triangular, divided by a transverse fold in about middle of length; basal area with a median furrow bordered by carinae; apical area nearly flat; apex obtuse (fig. 48). Cerci conical. Subgenital plate simple, with apex obtusely angularly rounded (fig. 49). Ovipositor short; apices of dorsal and ventral valves hooked; dorsal and ventral valves with 2-4 minute teeth (fig. 50).

Coloration. - Antennae brown, darker towards apex. Frons dark brown; genae ivory white with a dark brown stripe from compound eye to mandible. Vertex and pronotal disc dark brown with light bands bordering the fastigium, then running along inner margin of compound eyes and straight back, bordering pronotal disc and continuing on tegmina. Lateral lobes of pronotum dark brown above, ivory white below middle, dark brown at ventral margin. Tegmina medium brown with a whitish band along cubital veins; costal field dark brown. Pleurae dark brown with ivory white markings. Abdominal tergites dark brown medially, yellow laterally and along hind margins. Sternites yellow (? green when alive); mesometasternal plate with blackish brown lateral margins (in female only partly developed). Fore and mid legs green. Hindfemur green, about apical third red, hind knees dark brown. Hindtibia blue, base black with a white spot at top. Hindtarsus yellow.

Measurements. - Body ô 17, $q$ 20; pronotum 


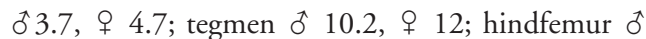
10.7, ㅇ 12; antenna ô 10 , 우 7 ; fastigium verticis in front of eyes $\delta 0.7$, $q 0.8$; interocular distance $\delta$ 0.7 , $९$ 0.9; eye length ô 2.2, $q$ 2.6.

\section{Discussion}

The male of the new species is similar to the holotype of O. aurora (Brunner 1893) as re-described by Ingrisch (1989), except for shorter wings (10.2 against $16.5 \mathrm{~mm}$ ), the absence of the preapical tooth on the cercus, and the hind knees with being only infumate on the upper area instead of being fully dark brown. Unfortunately, the phallic complex was pulled off and got lost before we studied the specimen, thus the shapes of the lophi of the epiphallus could not be compared. The genus Oxytauchira Ramme, 1941 contained so far seven local species; a key to the species from mainland Asia is given in Ingrisch (1989). Although a common basic structure of the male epiphallus is derived between species, all species can be readily distinguished using external characters. The shape of the cerci and the colour pattern of the hind femur were found to be diagnostic features (Ingrisch 1989). We are thus certain that the Meghalayan specimens are not conspecific with $O$. aurora, despite the fact that the phallic complex is missing. The female of $O$. aurora is still unknown. The combination of coloration of the hind femora, trilobate prosternal process, simple conical male cercus and wing length make $O$. jaintia distinctly different from other members of the genus, such as O. brachyptera Zheng, 1981 (Yunnan, North Thailand), O. oxyelegans Otte, 1995 [replacement name for $O$. elegans Zheng \& Liang, 1986 (Yunnan) probably a synonym of $O$. brachyptera Zheng, 1981 (Ingrisch 1989)], O. bilobata Ingrisch, 1989 (Thailand), O. aspinosa Ingrisch, 1989 (Thailand), O. elegans F. Willemse, 1965 (Java), and O. gracilis (C. Willemse, 1931) (Sulawesi).

The genus Oxytauchira is listed under the Catantopinae s.l. in the Orthoptera Species File Online. However, here we adopt the view of Hollis (1975) and arrange it with the Oxyinae.

\section{Etymology}

Named after its occurrence in the hills of Jaintia (a noun in apposition).

\section{Coptacridinae}

\section{Eucoptacra abbreviata sp. n.} (figs. 51-56)

Type material. - Holotype $q$, Manipur, Mao, M.E. School, 16.ix.1975, M. S. Shishodia.

\section{Description}

Agrees with generic description in C. Willemse (1957). Frontal ridge distinct throughout (fig. 56); between antennae about as wide as fastigium verticis between eyes $(11.5: 11.0)$. Vertex with a median carina between eyes to almost hind margin of vertex. Index interocular distance : eye length 0.18 ; one eye $1.6 \times$ longer than subocular furrow. Pronotum with principle sulcus in middle of sixth tenth of pronotum length. Prosternal spine short, conical; apex subacute. Mesosternal lobes $1.5 \times$ wider than long; mesosternal interspace $1.56 \times$ wider than long; metasternal lobes separate (fig. 51). Tegmina not completely covering abdomen, reaching about middle of hindfemur; anterior margin with a dilation; apex narrow, obliquely convex; without fascia. Hind wings about $1 \mathrm{~mm}$ shorter than tegmina. Hindfemur with dorsal and ventral keels almost smooth; ventral genicular lobe truncate.

Male. - Unknown.

Female genitalia. - Tenth abdominal tergite largely divided in middle but contiguous at very base. Supraanal plate elongate triangular, lateral areas sloping, apex obtuse; with a transverse fold in middle; basal half with a very shallow median furrow. Cerci short, conical, not reaching tip of supra-anal plate. Ovipositor valves obtusely hooked at apex; margins subsmooth (fig. 53). Subgenital plate with apical margin triangular in middle, concave at both sides (fig. 52).

Coloration. - Almost uniformly brown. Pronotum with disc a little darker than lateral lobes. Tegmen medium brown, subtransparent towards apex. Hindfemur medium brown, dorsal area with two indistinct dark spots; outer area with a row of small black spots on dorso-external carina; ventro-external area black with black colour extending a little onto lateral area twice; ventro-internal area and ventral margin of internal area red; otherwise internal area brown with two black spots (spot in middle restricted to dorsal half of femur). Base of hind knees indistinctly darkened on all sides. Hindtibia red; tips of spines black.

Measurements. - Body 19; pronotum 4.8; tegmen 9.0; hindfemur 12.5; antenna broken; fastigium verticis in front of eyes 0.7 ; interocular distance 0.5 ; eye length 2.6.

\section{Discussion}

The genus Eucoptacra Bolívar, 1902 contains 25 species, eight of them occur in east and southeast Asia, the others in Africa. This is so far the only species of Eucoptacra with abbreviated wings and the apex of the tegmina being obliquely convex instead of distinctly truncate as in other species of the genus. All other known species are long-winged and of different appearance, compared with specimens at hand of $E$. praemorsa (Stål, 1861), E. saturata (Walker, 1870), E. ceylonica Kirby, 1914, E. binghami Uvarov, 1921, and 
with descriptions in Tinkham (1940), Yin (1984) or Balderson \& Yin (1987) of E. kwantungensis Tinkham, 1942 (Kwantung, S. China) and E. motuoensis Yin, 1984 (Motuo, Xizang).

The limits between the SE Asian coptacridine genera are badly defined and a revision would be most welcome. Several of the species of the following genera were originally described under Eucoptacra. Therefore, the new species has also been compared and found to be distinct from Coptacrella Bolívar, 1902, Epistaurus Bolívar, 1889, Apalacris Walker, 1870, and Coptacra Stål, 1873. Some species of the latter genus seem to be variable in wing length but the taxonomic significance of this variability is unknown.

\section{Etymology}

Named after the abbreviation of the wings.

\section{Catantopinae (s. 1.)}

The systematics of the family Acrididae is still far from resolved. The Catantopinae as understood by the time of Mishchenko (1952) and C. Willemse (1956, 1957) was later split in nearly twenty subfamilies. Most of them comprise distinct forms and contain only between three and less than forty genera, an exception are the Holarctic Melanoplinae with nearly 130 genera. The majority of genera however was left in the Catantopinae; currently 380 genera are listed under this subfamily (Otte et al. 2004). The Catantopinae are further divided into 17 tribes. However 16 of those tribes contain only one to four genera. Only the Catantopini contain 142 genera, but this number is exceeded by the 210 genera in Catantopinae that are not assigned to a tribe (Otte et al. 2004).

\section{Assamacris spinipicta sp. n.}

(figs. 57-80)

Type material. - Holotype ô: Manipur, Mao, Songsang, 5762 ft, 13.ix.1975, M. S. Shishodia. Paratype 19 : same data.

\section{Description}

Head conical, in lateral view distinctly oblique in male (but less so than in A. striata), in female almost vertical; frontal ridge projecting between antennae, subobsolete below transverse facial sulcus; lateral facial carinae present but rather flat, running close and parallel to subocular grooves; genae with an oblique furrow; frons with impressed dots (figs. 59, 62). Index interocular distance : eye length 0.16 (male) or 0.26 (female); eyes $1.7 \times$ (male) or $1.4 \times$ (female) longer than subocular furrow. Pronotum rugose (with impressed dots); median carina only indicated by a smooth line; lateral margins of disc angularly rounded; with 4 transverse sulci, the first sulcus restricted to lateral lobes, only the fourth (= principle) sulcus entire, second and third sulci shortly interrupted in midline; anterior and posterior margins convex but anterior margin slightly concave in middle, in male also posterior margin. Prosternal spine small, conical; apex subacute (figs. 68-69). Brachypterous, tegmina reaching about fifth abdominal tergite in male, seventh tergite in female. Mesosternal lobes $1.2 \times$ (male, fig. 63) or $1.4 \times$ (female, fig. 67) wider than long; mesosternal interspace $1.15 \times$ longer than wide. Hindfemur rather slender. Hind knees with ventral lobe triangular (female) or triangularly rounded (male).

Male genitalia. - Tenth abdominal tergite excised in middle but entire, with short, obtuse furculae (fig. 64). Supra-anal plate shield-shaped with median area a little raised and shallowly furrowed; with indication of a transverse sulcus; lateral area little raised in basal half with a tubercle in middle of length; apex obtuse. Cerci terminating in a short, obtuse dorsal and a long acute ventral branch (figs. 65-66). Epiphallus with large, stout lophi projecting in a $90^{\circ}$ angle from bridge; anchorae large, hooked (figs. 73-75). Ectophallic membrane with extra sclerites: paired dorsal sclerites lying on the phallus and a large band-shaped ventral sclerite embracing the phallic complex ventrally and laterally (figs. 76-78). Aedeagal valves sheathed with the dorsal aedeagal sclerite projecting behind the sheath as a styliform projection; ventral aedeagal valves as long as the sheath of the dorsal valves (figs. 79-80).

Female genitalia. - Tenth abdominal tergite entire. Supra-anal plate almost triangular with lateral areas sloping; with a wide and shallow median furrow, interrupted by a transverse fold in middle; apex obtuse (fig. 70). Cerci conical, apex subobtuse. Ovipositor robust, margins of valves without teeth; apices hooked (fig. 72). Apex of subgenital plate sinuate with lateral areas sloping; with a short angular flap in middle (fig. 71).

Coloration. - Brownish. Head with a light band from margins of fastigium verticis along inner margins of eyes and curved to occiput, continued as lateral bands on disc of pronotum and dorsal area of tegmina; in posterior area of pronotum interrupted by an oblique dark stroke; vertex between light bands of a darker brown, continued as chocolate brown median band on pronotum and dorsum of tegmen; vertex with postocular bands of the same colour, continued on dorsal area of lateral lobes of pronotum and lateral areas of tegmen; all three brown bands ornated with fine black lines at both margins; this colour pattern in female distinct, in male indistinct. Hindfemur yellowish brown; external and internal surfaces with incomplete dark brown fish bone patterns continued as faint dark spots on dorsal areas; hind knees indistinctly brown. Hindtibia yellowish olivaceous with brown longitudinal stripes; spines black. 
Measurements. - Body đิ 28, ㅇ 32; pronotum oิ

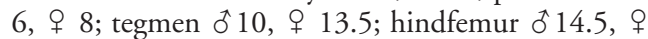
17.5; antenna $\delta$ broken, $q 15$; fastigium verticis in front of eyes $\hat{0} 0.8$, $q 0.9$; interocular distance $\hat{\sigma}$ 0.5 , ㅇ 0.8 ; eye length 0 t 2.8 , ? 3.3 .

\section{Discussion}

The new species differs from $A$. striata Uvarov, 1942 , by obtuse and wider dorsal lobe in the male cerci, the somewhat shorter ventral lobe; by the less oblique male face in lateral view; a brown fish-bone pattern on male and female hindfemora (not with 2 dark spots), by shorter tegmina in male; and less striking colour pattern. Huang (1981) described Tenuifemurus Huang, 1981, with two species T. longicercus Huang, 1981 (type-species) and T. curticercus Huang, 1981, from males from Xizang (Medog). Yin (1984) synonymized the latter genus with Assamacris Uvarov, 1942 , and recognized three species in the genus. The present species differs from both Xizang species by longer tegmina which are also of different shape. If the drawings in Huang (1981) and Yin (1984) are precise enough, the new species differs also in the presence of furculae on the tenth abdominal tergite and in details of the cercus apex. The phallus is not described for any of the other species. The female of the present species agrees with the female paratype of A. striata (seen by one of us, SI) except for the coloration of the hindfemur.

\section{Etymology}

Named after the contrasting coloration of hindtibia and its spines.

? Genimen yunnanensis Zheng, Huang \& Liu, 1988 (figs. 81-84, 109-112, 122-127)

Material studied. $-1 \hat{0}, 19$, Manipur, Burma border, Moreh, 2090 ft, 24.ix.1975, M. S. Shishodia.

Measurements. - Body đิ 19, + 24; pronotum $\delta$ 3.2, o 4.0; hindfemur ô 11.0, $q$ 12.0; hindtibia $\delta$ 9.0, ㅇ 10.0; hindtarsus ot 4.2, $q$ 4.0; antenna $\hat{o}+q$ broken; fastigium verticis in front of eyes $\delta 0.5$, $q$ 0.7 ; interocular distance $\hat{\delta} 0.2$, $q 0.3$; eye length $\widehat{\delta}$ 2.0 , 2.2 .

\section{Discussion}

The genus Genimen Bolívar, 1918 contained so far five species, described from South India, Sri Lanka, Myanmar and Yunnan. The specimens at hand agree with G. yunnanensis Zheng et al., 1988, in having similar coloration and black marking of the hind femur and having the furculae of the tenth abdominal tergite more pronounced than in G. burmanum Ramme, 1941. They are distinct from G. burmanum in the shape of the body being more fusifom, an appreciably divergent pronotum posteriorly and by their larger size. Moreover, G. burmanum has three yellow-white longitudinal stripes over pronotum and body (Ramme 1941, Willemse 1957) and not that these stripes are lacking, as might be supposed from the English diagnosis of G. yunnanensis in Zheng et al. (1988). The remarks in Zheng et al. may be erroneous as their figure of $G$. yunnanensis shows the median white stripe lacking except in the posterior area. In that case the difference between the two refers to G. yunnanensis having two lateral stripes only and G. burmanum having an additional median stripe (thus three instead of two).

In the specimens at hand a median white stripe on the pronotum is present, but narrower than usually in G. burmanum. However, they differ from the figures in Zheng et al. (1988) by a much wider fastigium. Thus there remains some doubt whether they really belong to G. yunnanensis. The phallic complex was taken off before our study and is now missing.

Genimen lailad sp. n.

(figs. 85-87, 92-98, 113-115)

Type material. - Holotype ô: Meghalaya, La-ilad, 20.v.1980, C. R. Krishnan.

\section{Description}

Head conical; anterior margin in lateral view concave; frontal ridge projecting between antennae, obsolete below transverse facial furrow; lateral facial carinae straight, subocular furrow subobsolete. Index interocular distance : eye length 0.10 ; one eye $2.1 \times$ longer than subocular furrow. Pronotum rugosely punctured; anterior margin convex; posterior margin concave; median carinae indicated by a smooth line, not elevated, interrupted by last (= principle) sulcus only. Prosternum as a whole bulging; prosternal spine small, conical, acute. Mesosternal lobes $1.1 \times$ wider than long; mesosternal interspace $1.2 \times$ wider than long; metasternal lobes contiguous (fig. 87). Apterous. Abdominal tympana reduced, not larger than stigma. Tibiae and tarsi (especially of hind legs) strongly setose. Hindtibia with 8 dorso-external and 9 dorso-internal spines; without dorso-external apical spine.

Male genitalia. - Ninth and tenth abdominal tergites separate and entire; tenth tergite constricted but contiguous in midline, with acute triangular furculae (fig. 86). Supra-anal plate shield-shaped; lateral margin a little constricted in middle, roundly curved mediad before apex; apex with a short triangular expansion; surface with central area little raised, with a transverse furrow. Cerci conical, apex subacute (fig. 85). Epiphallus in dorso-apical view with bridge almost straight; lophi projecting in a $90^{\circ}$ angle from bridge, undulate; ancorae conical, acute (figs. 92-93). Aedeagal valves sheathed, in lateral view acute-triangular with the ventral valves hidden by the dorsal 
valves, not projecting; membranes embedding the ramus forming large sacculiform projections covering the aedeagal valves in basal half (figs. 94-98).

Female. - Unknown.

Coloration. - Dorsal aspect black with yellow stripes, ventral aspect brown. Antenna blackish brown (tip concolorous). Frons black with symmetrical yellow marks as in fig. 115; genae yellow with ventral margin black and with some additional small black spots. Fastigium verticis yellow with black margins; vertex yellow with a large triangular black spot in middle and black postocular bands. Pronotum black; disc with a narrow median and with broader yellow lateral stripes; lateral lobes in dorsal part black, in ventral part yellow but ventral margin again black. Epimerum of mesoand metathorax black with a broad yellow stripe in middle. Abdomen from above black with a narrow median and broader lateral longitudinal yellow stripes; lateral area black with a rather narrow yellow band along margin. Prosternum blackish brown with spine yellow. Sternal plate yellowish brown with dark brown lateral margins. Abdominal sternites brown, darker in middle, lighter at lateral margins. Fore and mid legs yellowish brown (? green when alive), without maculation; very tip of tibiae darkened. Hindfemur yellow without extensive markings in basal half, only a black spot on dorsal area and a little conspicuous spot at ventral margin; in apical half with a complete black ring; hindknees black. Hindtibia black at condylus, otherwise dorsal and lateral surfaces dirty yellow (possibly discoloured); apex, spines and ventral surface brownish infumate. Hindtarsus yellowish brown.

Measurements. - Body 20; pronotum 3.2; hindfemur 11.0; hindtibia 9.0; hindtarsus 4.0, antenna 13; fastigium verticis in front of eyes 0.7 ; interocular distance 0.2 ; eye length 2.1 .

\section{Discussion}

The new species is close to G. yunnanensis in size and coloration. It differs in having slightly stronger furculae of the male tenth abdominal tergite, the slender male cerci, a yellow instead of orange coloured praegenicular area of hind femur, and in the shape of the epiphallus as figured by Zheng et al. (1988).

\section{Etymology}

This species is named after its type-locality, Lailad (a noun in apposition).

\section{Genimen amarpursp. n.}

(figs. 88-91, 99-108, 116-121)

Type material. - Holotype 0 : South Tripura, Amarpur, 12.vi.1990, G. N. Saha. - Paratype 19 : same data.

\section{Description}

Head conical; anterior margin in lateral view concave; frontal ridge projecting between antennae, obsolete below transverse facial furrow; lateral facial carinae straight; subocular furrow subobsolete. Index interocular distance : eye length 0.10 (male) or 0.17 (female); one eye $2.3 \times$ (male) or $1.9 \times$ (female) longer than subocular furrow. Pronotum rugosely punctured; anterior margin rounded; posterior margin broad-angularly excised; median carinae indicated by a smooth line, not elevated, interrupted by last (= principle) sulcus only. Prosternum as a whole bulging; prosternal spine small, conical, acute. Mesosternal lobes $1.2 \times$ (male, fig. 90) or $1.3 \times$ (female, fig. 105) wider than long; mesosternal interspace $1.1 \times$ (male) or $1.4 \times(\mathrm{fe}-$ male) wider than long; metasternal lobes contiguous (both sexes). Apterous. Abdominal tympana rather large. Tibiae and tarsi (especially of hind legs) strongly setose. Hindtibia with 8 dorso-external and 9 dorsointernal spines; without dorso-external apical spine.

Male genitalia. - Ninth and tenth abdominal tergites partly fused; ninth tergite lateral, narrow (fig. 88); tenth tergite divided in middle, with small furculae (fig. 89). Supra-anal plate with converging lateral margins, distinctly constricted before apex; with a small rounded apical flap; central area of surface in basal half a little elevated and furrowed; lateral areas and median area in apical half very shallowly grooved. Cerci conical, apex obtuse. Epiphallus with lophi projecting in a more than $90^{\circ}$ angle from bridge; lophi roughly triangular with undulating margins and obtuse angle; anchorae small, acute (figs. 99-100). Phallus with aedeagal valves strongly prolonged, sheathed with sheaths partly fused; ventral valves projecting behind dorsal valves; aedeagal valves in basal area covered laterally by large, membranous sheaths; zygoma of cingulum with obtuse apico-lateral projections (figs. 101-103).

Female genitalia. - Tenth abdominal tergite entire in midline. Supra-anal plate about triangular with lateral areas sloping, with a shallow baso-median impression, apex obtuse (fig. 107). Cerci conical, apex obtuse. Ovipositor short; valves subsmooth; apices hooked (fig. 104). Subgenital plate longer than broad; apex with an acute-triangular projection (fig. 108).

Coloration. - Dorsal aspect black with yellow stripes, ventral aspect yellowish. Antennae blackish brown, tip (apex of last segment) yellow. Frons and frontal ridge yellow with symmetrical black spots as in Fig. 118; genae yellow with ventral margin black and with some additional small black spots. Fastigium verticis yellow with black margins; vertex yellow with a large triangular black spot in middle and black postocular bands. Pronotum black; disc with a narrow median and with broader yellow lateral stripes; lateral lobes in dorsal part black, in ventral part yellow but ventral margin again black. Epimerum of meso- and metatho- 
rax black with a broad yellow stripe in middle. Abdomen from above black with a narrow median and broader lateral longitudinal yellow stripes, lateral area broad yellow. Sternites yellow. Fore and mid legs with femora and tarsi yellow, tibiae bluish-green. Hindfemur yellow; outer area in basal half with a $\mathrm{V}$ - (male) or Y- (female) shaped black marking; in apical half with a complete black ring; dorsal area with a distinct (female) or indistinct (male) small basal black spot, a little before middle with a black transverse spot, connected with the $\mathrm{V}$ - or Y-shaped marking of the outer area; hind knee black. Hindtibia black at the condylus with a dirty yellow basal ring, otherwise blue with apex infumate. Hindtarsus yellow.

Measurements. - Body ot 16, $q$ 21; pronotum $\widehat{\delta}$ 2.8, ㅇ 3.5; hindfemur ô 9.5, 우 11.0; hindtibia ot 8.0, ㅇ 9.0; hindtarsus ô 3.8, ㅇ 4.2; antenna ô 11, 우 9; fastigium verticis in front of eyes $\widehat{o} 0.5$, $q 0.6$; interocular distance ôे 0.2 , 90.4 ; eye length ôे 2.0 , $९ 2.1$.

\section{Discussion}

The new species is similar to G. burmanum Ramme, 1941. It differs in having yellow instead of red sternites and lateral margins of the abdomen, in having a $\mathrm{V}$ shaped marking instead of Y-shaped marking on the male hindfemur. Moreover, the male is a little larger than G. burmanum, the supra-anal plate has a distinct preapical constriction, and the tarsi are longer. In the female the mesosternal interspace is narrower than the mesosternal lobes while in the G. burmanum female it is wider, and the metasternal lobes are contiguous rather than subcontiguous in G. burmanum. The new species is also close to $G$. prasinum Bolívar, 1918. From that species it differs by the body being more fusiform instead of slender, in having the integument dotted or foveolate instead of smooth, by the tympanum being relatively large and open while in prasinum it is almost vestigial, and by the Y-shaped marking on the hindfemur of the female. The phallic complex of both other species is still undescribed.

\section{Etymology}

This species is named after its type-locality, Amarpur (noun in apposition).

\section{Apalniacris gen. n.}

Type species: Apalniacris dampha sp. n.

\section{Description}

Head conical; anterior margin in lateral view concave. Antennae distinctly longer than head and pronotum together; basal segments of flagellum compressed and little widened. Frontal ridge projecting between antennae, shallowly furrowed, constricted at transverse facial furrow, indistinct below transverse facial furrow. Frons with some furrows and impressed dots but not really rugose; lateral facial keels distinct throughout; subocular furrow very shallow; with an oblique furrow on genae; mandibles with a vertical carina parallel to posterior margin. Fastigium verticis shallowly impressed or furrowed in middle; with shallow foveolae; vertex with a low median carina. Pronotum rugose; lateral lobes in dorso-anterior area mat and in dorso-central area smooth and shining; disc somewhat roof-shaped but not much raised, lateral margins angularly rounded into lateral lobes; anterior margin slightly convex at both sides and weakly excised in middle; median carina distinct, cut by three transverse sulci, depressed at anterior margin; areas lateral of carina more or less bulging near anterior margin; posterior margin truncate or slightly angular or faintly convex at both sides, always angularly excised in middle, with a series of elongate tubercles. Squamipterous; tegmina lanceolate. Abdominal tympana large, only partly covered by tegmina. Prosternal spine conical, apex subacute. Mesosternal lobes wider than long; mesosternal interspace about as wide as or wider than long; metasternal lobes subcontiguous or separate in male (figs. 128, 133, 138, 143), always separate in female (figs. 175, 178, 182). Hindfemur moderately thick; dorso-median carina finely serrulate (with low and spaced teeth), terminating in a spinule; dorsoexternal area rugose; lateral areas shining; lower genicular areas obtuse. Hindtibia with 6-7 dorso-external and 9 dorso-internal spines, without dorso-external apical spine.

Male genitalia. - Tenth abdominal tergite furrowed or divided in midline, with furculae (figs. 130, 135, 140, 145). Supra-anal plate varying between species. Paraprocts with a large projection (Fig. 141). Cerci modified, often strongly curved and apex compressed or widened (figs. 132, 142, 146, 137). Subgenital plate short, conical. Epiphallus with lateral areas often distinctly curved ventrad. Phallus with aedeagal valves small; basal fold and ventral infold both with distinct sclerites, covering central parts of phallus dorsally and ventrally.

Female genitalia. - Supra-anal plate long triangular, with a median furrow in basal half and with an indistinct transverse fold in or behind middle of length; lateral areas sloping; apex obtuse (figs. 181, 185). Cerci conical, often wide at base (figs. 177, 180, 184). Subgenital plate with apical margin varying between species. Ovipositor short, margins without teeth, apices of valves hooked; ventral margins of dorsal valves, dorsal margins of ventral valves and dorsal margin of basivalvular sclerite with long hairs.

Coloration. - Brown with irregular light and dark pattern. Frons often yellowish brown with dark spots (male) or light to medium brown with indistinct dark speckles (female). Vertex with broad black postocular 
bands, bordered medially by a narrow white band. Pronotum with disc brown, with or without light lateral bands; lateral lobes usually with a large black spot in centro-dorsal area, white along ventral margin. Fore and mid legs light brown (possibly green when alive) with dark spots. Hindfemur with two oblique black bands separated by a narrow white band, ventral areas reddish-brown.

\section{Discussion}

Differs from Palniacris Henry, 1940, by the frontal ridge that distinctly projects between the antennae, rendering the frons distinctly oblique and concave in lateral view (not faintly conical or almost vertical in female); by the pronotum which has a truncate apical margin that is excised in middle instead of an angular apical margin; by the tegmina which are parallel-sided and not widened towards apex; by the male terminal tergite and supra-anal plate. Remarkably for the new genus are also the large projections of the paraprocts.

Apalniacris has also been compared with the monotypic Eucnemidia Ramme, 1941 (= Burmacris Uvarov, 1942). In E. charlottae Ramme, 1941, the pronotal lateral keels are distinct, the prosternal process is flattened with an obtuse apex, the tegmen is apically pointed, the frontal ridge is not roundly extending frontally between the eyes, and the lower genicular lobes are spined. Furthermore, the hind femur is somewhat attenuate.

The new genus may also be allied to Traulia Stål, 1873 and also has some superficial resemblance to Sedulia Stål, 1878, Mesambria Stål, 1878, Pagdenia Miller, 1934 (monotypic genus from Malaya), Bibracte Stål, 1878, Squamobibracte Ingrisch, 1989, and Urugalla Uvarov, 1927. The species described here, however, are clearly distinct from those in the other genera.

Circocephalus Willemse, 1928 (with certainty only known from the male holotype from Java [examined by $\mathrm{FW}]$ ) has the profile of the head rounded as a circle (hence its name) and is thus rather distinct from the new genus with a projecting frontal ridge between the eyes. It is questionable whether Circocephalus indica Bhowmik, 1982, from West Bengal, Darjeeling, and Circocephalus maculatus Zheng, 1985, from the Heilongjiang province in China really belong to Circocephalus and not to Apalniacris or another genus.

For the time being, Apalniacris is arranged under the Catantopinae and here within the large group of genera not assigned to any tribe.

\section{Etymology}

Named after some reminiscence to Palniacris (gender feminine) but with the Greek prefix a - because it differs obviously from that genus.
Apalniacris jalpaiguri sp. $\mathrm{n}$.

(figs. 128-132, 147-150, 161-163, 175-177, 188-

189, 196-197, 201, 203)

Type material. - Holotype đ: W. B., Jalpaiguri Dist., Chilapata, 14.x.1987, M. S. Shishodia.

Other material examined. - 19 (? same species), W. B., Darjeeling, Sevok, 1.x.1979, A. K. Singh.

\section{Description}

Lateral facial keels slightly diverging ventrally (male) or parallel (female). Fastigium verticis shallowly impressed; fastigial foveolae small and quadrangular (male) or triangular (female). Index interocular distance : eye length 0.31 (male) or 0.37 (female); one eye $2.4 \times$ (male) or $2.0 \times$ (female) longer than subocular furrow. Pronotum along hind margin with 6 tubercles on disc and 3 tubercles at each paranotum (male) or 5 tubercles on disc and 2-4 tubercles at each paranotum (female). Tegmen with apex angularly rounded (male) or obliquely truncate (female). Mesosternal lobes $1.4 \times$ wider than long; mesosternal interspace as long as wide (male) or $1.1 \times$ wider than long (female); metasternal lobes subcontiguous (male, fig. 128), separate (female, fig. 175).

Male genitalia. - Tenth abdominal tergite furrowed in midline and with long, acute furculae (fig. 130). Supra-anal plate roughly pentagonal with wide basal and triangular apical areas; in midline with a shallow groove at base and a narrow furrow in apical half. Paraprocts with a large auricular projection. Cerci slightly surpassing supra-anal plate; curved, narrowest in middle, apical area compressed and widened; apex subtruncate with angles rounded (figs. 129, 132). Epiphallus with lateral areas curved ventrad; lophi pointing apicad, obtuse; bridge arch-shaped; ancorae strongly curved proximo-ventrad, their acute apices only seen in anterior view (figs. 147-149). Sclerite of dorsal fold damaged, probably about band-shaped; sclerite of ventral infold with large lateral lobes and a strong constriction in midline (figs. 161-162). Phallus with aedeagal valves curved dorsad, dorsal valves stylate, ventral valves flattened, broad in apical view (fig. 163).

Female genitalia. - Cerci conical, compressed, short, very wide at base (fig. 177). Subgenital plate with apex slightly trilobate (fig. 176).

Coloration. - Male. Frons yellowish brown; frontal ridge with a black spot above and another below median ocellus; area around antennal grooves black; apical areas of labrum and mandibles dark brown; palpi yellow. Antennae blackish brown, lighter towards apex. Eyes rufus. Vertex suffused with black in middle, with white and black postocular bands. Pronotal disc with an indistinct dark median and indistinct light lateral bands; lateral lobes blackish brown with a large white spot in ventral area. Tegmen almost white 
in dorsal, blackish brown in ventral area. Fore and mid legs light with dark brown maculation. Hindfemur light brown at base; external area with a dark spot at base and two large, oblique, transverse, blackish brown bands interrupted by a white band, the apical black band extending on ventral areas; with a white pre-apical spot; hind knees darkened; dorso-external area light in basal third, otherwise dark brown; internal area as external area but dark bands less wide; ventral areas reddish-brown, towards apex blackish brown, then white, then blackish brown. Hindtibia blackish brown in more than basal half, interrupted by a white ring; little more than apical third reddish brown. Hindtarsus with first segment light, other segments dark brown.

Female. As in male but frons with indistinct dark speckles. Antennae with light margins and dorsal surface less dark than ventral surface. Disc of pronotum uniformly brown with some maculation at apical margin; lateral lobes with indistinct white spot.

Measurements. - Body ô 24, ㅇ 26; pronotum to 4.2, ㅇ 6; tegmen $\delta$ 3.3, ㅇ 4.5; hindfemur 0 12, 우 14; antenna of 12 , broken in + ; fastigium verticis in front of eyes $\hat{\sigma} 0.7$, +90.9 ; interocular distance $\hat{\sigma}$ 0.8 , ㅇ 1.1; eye length ô 2.6, $q$ 3.0.

\section{Discussion}

The male of $A$. jalpaiguri differs from other Apalniacris species by the very large furculae of the tenth $a b-$ dominal tergite, the cerci with strongly widened apex, and by details of the phallic complex, and the female by the trilobate apex of the subgenital plate.

\section{Etymology}

Named after its occurrence in the district of Jalpaiguri (a noun in apposition).

\section{Apalniacris dampha sp. $\mathrm{n}$.}

(figs. 133-137, 151-154, 164-167, 178-181, 186-

$187,194-195,200,204)$

Type material. - Holotype $\delta$ : Mizoram, Aizawl, Dampha Wildlife Sanctuary, Teirei, 22.x.1991, J. K. Jonathan. - Paratype 1 9 : same data, but 24.x.1991.

\section{Description}

Frons with lateral facial keels parallel; fastigial foveolae triangular in both sexes; fastigium verticis furrowed in midline. Index interocular distance : eye length 0.29 (male) or 0.35 (female); one eye $2.3 \times$ (male) or $2.0 \times$ (female) longer than subocular furrow. Pronotum along hind margin with 3 tubercles on disc and 3 tubercles at each paranotum (male) or 4 tubercles on disc and 4-5 tubercles at each paranotum (female). Tegmen with apex rounded in both sexes. Mesosternal lobes $1.3 \times$ wider than long; mesosternal interspace $1.1 \times$ longer than wide (male) or $1.1 \times$ wider than long (female); metasternal lobes subcontiguous (male, fig. 133), separate (female, fig. 178).

Male genitalia. - Tenth abdominal tergite divided in middle, with moderately large, obtuse furculae (fig. 135). Supra-anal plate roughly triangular with convex lateral margins, with a preapical constriction and apex curved ventrad; with a median furrow that is wide and shallow at base, narrow and deep at apex. Paraprocts with a large auricular projection. Cerci with basal third conical, distally compressed, band-shaped; strongly curved mediad and later dorsad; apex obtuse (figs. 134, 137). Subgenital plate setose. Epiphallus with lateral areas curved ventrad; lophi pointing dorso-anteriorly, roughly triangular with obtuse apex and curved margins; anchorae pointing anteriorly, acute (figs. 151-153). Sclerite of basal fold roughly Vshaped with stout arms and an apicomedian projection; sclerite of ventral infold broad band-shaped with angular excision in middle of proximal margin, apical margin undulating (figs. 164-165). Phallus with elongate dorsal aedeagal valves and conical ventral aedeagal valves (figs. 166-167).

Female genitalia. - Cerci short, triangular, wide at base; apex tuberculate (fig. 180). Subgenital plate with apical margin slightly convex (fig. 179).

Coloration. - Male. Antennae blackish brown, apex white. Eyes rufus. Frons yellowish brown; antennal scrobae and area around them and frontal ridge above median ocellus black except for a light spot above median ocellus; with additional small black spots at frontal ridge, lateral facial keels and clypeus; ventral areas of labrum and mandibles blackish brown; palpi dirty yellow. Vertex with a dark median band, eyes posteriorly bordered by wide light bands, followed by narrow black and narrow white bands and broad black postocular bands. Pronotal disc with an indistinct dark median and indistinct light lateral bands; lateral lobes blackish brown with a large white spot in ventral area. Tegmen almost white in dorsal, blackish brown in ventral area. Fore and mid legs light with dark brown maculation. Hindfemur light brown at base, with two large, oblique, black bands interrupted by a white band; with a white preapical spot in ventral area; hind knees dark; ventral areas reddish brown, towards apex with two black bands interrupted by a white band. Hindtarsus with first segment light, other segments dark brown.

Female. As male but pattern on head and pronotum more distinct. Frons mottled medium brown with black spots as in male.

Measurements. - Body ơ 24, + 24; pronotum $\delta$ 3.8, क 5.2; tegmen ô 3.0, क 4.0; hindfemur ô 11.0, o 13.5; antenna ot 11 , $q 12$; fastigium verticis in front of eyes $\delta 0.6$, $q 0.8$; interocular distance $0 \hat{0} 0.4$, ㅇ 1.0; eye length ơ 2.5 , ㅇ 2.8 . 


\section{Discussion}

The male of $A$. dampha differs from all other Apalniacris species by the cerci having the long apical area curved dorso-mediad and by details of the phallic complex; from $A$. jalpaiguri by the shorter furculae of the tenth abdominal tergite and from $A$. ukhrul and A. shillong by the narrow apex of the supra-anal plate. The female differs from all other known Apalniacris females by the very short, triangular cerci.

\section{Etymology}

The name is derived from the Dampha Wildlife Sanctuary, a noun in apposition.

\section{Apalniacris ukhrulsp. n.}

(figs. 138-142, 158-160, 172-174, 182-185, 192-

193, 198-199, 202, 205)

Type material. - Holotype ô: Manipur, Ukhrul, 16.xi.1983, S. K. Gupta. - Paratypes: $1+$, same data; 10े, same, but 17.xi.1983.

\section{Description}

Fastigial foveolae triangular in both sexes. Index interocular distance : eye length $0.39-0.40$ (male) or 0.49 (female); one eye $2.5 \times$ (male) or $1.7 \times$ (female) longer than subocular furrow. Pronotum along hind margin with 2-3 tubercles on disc and 2-3 tubercles at each lateral lobe. Tegmen with apex obliquely truncate in both sexes. Mesosternal lobes $1.15 \times$ wider than long (male) or $1.3 \times$ wider than long (female); mesosternal interspace 1.2-1.4X wider than long (both sexes); metasternal lobes subcontiguous or narrowly separate (male, fig. 138), widely separate (female, fig. 182).

Male genitalia. - Tenth abdominal tergite divided in middle, with moderately large furculae (fig. 140). Supra-anal plate shield-shaped, constricted before apex; apex with a short, rounded, median flap (curved ventrad but this may be an artefact); with a median furrow in basal half; transverse fold little conspicuous; with a median and with lateral very shallow grooves in apical half. Paraprocts with a large projection (fig. 141). Cerci conical, moderately curved mediad, apical area compressed; apex rounded (figs. 139, 142). Epiphallus with lateral areas curved ventrad; lophi pointing dorsad, with undulating margins; anchorae robust (figs. 158-160). Sclerite of basal fold roughly broad-U-shaped; anterior margin undulating with a short obtuse excision in middle; apical margin broadly rounded with a short, obtuse projection in middle (fig. 172). Phallus with dorsal aedeagal valves narrow, elongate, ventral aedeagal valves cone-shaped (figs. 173-174).

Female genitalia. - Cerci short, conical (fig. 184). Subgenital plate with apical margin angularly rounded (fig. 183).
Coloration. - Male. Frons yellow; frontal ridge with a black spot above and below median ocellus; additional black spots may appear elsewhere on frons; antennal scrobae and area around them black; apical areas of labrum and mandibles dark brown; palpi yellow. Antennae blackish brown with light or concolorous margins, little lighter on dorsal surface. Eyes rufus. Vertex and disc medium brown (without bands), followed by a narrow black, a narrow white and a broad black postocular band at each side. Pronotal disc with an indistinct dark median and indistinct light lateral bands; lateral lobes blackish brown with a large white spot in ventral area. Sternal plate with anterior margin, mesosternal interspace, lateral areas of metasternum and sutures blackish brown. Tegmen almost white in dorsal, blackish brown in ventral area. Fore and mid legs light with dark brown maculation. Hindfemur light brown at base; external area with a dark spot at base and two large, oblique, transverse, blackish-brown bands interrupted by a white band, the apical black band extending on ventral areas; with a white pre-apical spot; hind knees darkened; dorso-external area light in basal third, otherwise dark brown; internal area as external area but dark bands less wide; ventral areas reddish brown, towards apex blackish brown, then white, then blackish brown. Hindtibia blackish brown in more than basal half, interrupted by a white ring; little more than apical third reddish brown. Hindtarsus with first segment light, other segments dark brown.

Female. Almost uniformly ochreous brown with markings little conspicuous. Frons as in male; vertex with postocular bands present but narrow, not wide, reduced in ventral area. Lateral lobes of pronotum brown without black and white spots. Hindfemur with only one black band conspicuous.

Measurements. - Body đิ 16-17, o 26; pronotum o 3.7-3.8, o 5.3; tegmen ô 2.8-3.0, o 4.3; hindfemur ô 9.7-10.0, o 13.5; antenna ô 8-9, क 8; fastigium verticis in front of eyes $\hat{0} 0.7$, $q 0.9$; interocular distance $\hat{o} 0.8$, ㅇ 1.1 ; eye length $\hat{o} 2.0-2.1$, $q$ 2.3.

\section{Discussion}

The male of $A$. ukhrul differs from A. jalpaiguri and $A$. dampha by the wide apex of the supra-anal plate and by the simple cerci with narrow rounded apex, not widened nor without long median projection. The cerci also differ from those of $A$. shillong in that they are gradually narrowing towards apex rather than narrowest in middle and faintly widening towards apex. From all three other Apalniacris species it differs by details of the phallic complex. In the female, the cercus is rather long if compared to that of $A$. jalpaiguri or $A$. dampha.

\section{Etymology}

Named after the locality of the species, Ukhrul (a noun in apposition). 
Apalniacris shillong sp. $\mathrm{n}$.

(figs. 143-146, 155-157, 168-171, 190-191)

Type material. - Holotype 0 : Meghalaya, Shillong, Motinagar, 21.xi.1974, R. S. Giri.

\section{Description}

Fastigial foveolae triangular. Index interocular distance : eye length 0.37 ; one eye $2.7 \times$ longer than subocular furrow. Pronotum along hind margin with 4 tubercles on disc and 3 tubercles at each paranotum. Mesosternal lobes $1.2 \times$ wider than long; mesosternal interspace $1.2 \times$ wider than long; metasternal lobes separate (fig. 143). Tegmen with apex obliquely truncate.

Male genitalia. - Tenth abdominal tergite divided in middle, with very small furculae (fig. 145). Supraanal plate curved dorsad; lateral margins little approaching each other posteriorly, apex broadly subtruncate (slightly convex); dorsal surface with a shallow median furrow at base and a pit before apex, otherwise undifferentiated; ventral surface with a transverse, arcuate preapical fold and slightly swollen at apex. Paraprocts with a rounded dorso-lateral and a rounded ventral projection (fig. 145). Cerci slightly conical in more than basal half, compressed and curved mediad in apical area; apex obtuse (figs. 144, 146). Epiphallus with lophi pointing dorso-apicad, rather narrow; apex rounded; anchorae conical, acute (figs. 155-157). Sclerite of basal fold broad at both sides, constricted in middle (fig. 168). Phallus with aedeagal valves short and small (figs. 170, 171).

Female. - Unknown.

Coloration. - Frons ochreous, furrow of frontal ridge above median ocellus and a spot below median ocellus black; antennal scrobae and area around them black. Pronotal disc with an indistinct dark median and indistinct light lateral bands; lateral lobes blackish brown with a large white spot in ventral area. Tegmen almost uniformly brown, dorsal area slightly paler. Hindfemur light brown at base; external area with a dark spot at base and two large, oblique, transverse, dark bands (the first blackish brown, the second chocolate brown) interrupted by a white band, the apical dark band extending on ventral areas; with a white preapical spot; hind knees darkened; dorso-external area light in basal third, otherwise brown; internal area as external area but dark bands less wide; ventral areas reddish-brown, towards apex chocolate brown, then white, then chocolate brown. Hindtibia blackish brown at base followed by a white ring, rest medium brown (possibly reddish when alive). Sternal plate with mesosternal interspace and sutures dark brown. Abdominal tergites with blackish brown lateral bands.

Measurements. - Body 18.5; pronotum 3.2; tegmen 3.3; hindfemur 3.0; antenna broken; fastigium verticis in front of eyes 0.7 ; interocular distance 0.7 ; eye length 2.0.

\section{Discussion}

The male of A. shillong differs from other Apalniacris species by the flattened supra-anal plate that is not at all narrowed at apex (the upcurved state of the specimen at hand is probably due to deformation at preparation), in the shape of the cerci which are narrowest in middle and faintly widening again towards apex, and in details of the phallic complex.

\section{Etymology}

Named after its range, Shillong (a noun in apposition).

\section{DisTRIBUTION}

All specimens reported in the present paper were collected in the northeastern part of India from Darjeeling in the west to Manipur and Mizoram in the east (fig. 206). It should thus be expected that taxa can be found that are not reported from other parts of India.

Regarding the distribution of the taxa concerned, Oxya velox and Eucoptacra abbreviata belong to genera that are widely distributed in the Oriental Region while the other genera have more limited ranges. Lem$b a$ species were so far only reported from South China: Sichuan and Yunnan (Huang 1983, Yin \& Liu 1987, Niu \& Zheng 1992, Ma et al. 1994, Ma \& Zheng 1994). The current record extends the known area to the west but otherwise is 'in line' with previous findings. Oxytauchira species were so far reported from Myanmar, North and Central Thailand, and Yunnan, and remote from that area with a single species each from Java and Sulawesi (C.Willemse 1931, F. Willemse 1965, Zheng 1981, Ingrisch 1989). The discovery of O. jaintia in Meghalaya extends the known area a little to the west.

Assamacris has a more restricted distribution and was first only known from the type species $A$. striata with the holotype from Cherrapunji, Meghalaya (fig. 206, originally reported as from Assam) and a female from the Mishmi Hills which now lie in Arunachal Pradesh (about $29^{\circ} 05^{\prime} \mathrm{N}, 95^{\circ} 55^{\prime} \mathrm{E}$, just outside the upper right angle of fig. 206). Two more species from Medog in Xizang (Tibet) were also assigned to the genus (Yin 1984). The type localities of $A$. striata and A. spinipicta lie in different, but neighbouring mountain ranges. They are closer to each other than to the locality of the female paratype assigned to $A$. striata by Uvarov (1942). Male specimens of Assamacris from the Mishmi Hills are required to decide on the question if the female paratype of $A$. striata is conspecific with the male holotype. More species of Assamacris should be expected to occur in the mountains of the triangle of Northeast India, China and Myanmar.

Five apterous species were previously included in the genus Genimen: G. prasinum Bolívar, 1918 (type species) from South India (Mysore, Bababuddin Hills), 
G. ceylonicum Uvarov, 1927, from Sri Lanka (Kandy), G. burmanum Ramme, 1941, from Myanmar (Chin Hills, Pakokku, Dudan Taung), G. victoriae Ramme, 1941, from Myanmar (Chin Hills, Mt. Victoria) and G. yunnanensis Zheng, Huang \& Liu, 1988, from China (Yunnan, Wanding). Their distribution is insufficiently known. The most widespread species seems to be so far G. burmanum. Apart from the type locality in the Chin Hills, Pakokku (Fig. 206), there are two more localities north of Rangoon (Ramme 1941) and it is also a common species in the mountainous region of northwestern Thailand (S. Ingrisch, unpublished). G. yunnanensis was described from the southwestern border area of Yunnan (Wanding: $24^{\circ} 05^{\prime} \mathrm{N} 98^{\circ} 04^{\prime} \mathrm{E}$ ). If the specimens from Manipur are really conspecific with those described by Zheng et al. (1988), G. yunnanensis probably replaces $G$. burmanum in the North and could be expected to occur also in northern Myanmar. G. victoriae is a mountain species so far only reported from Mt. Victoria between 1400-2800 m (Ramme 1941). The distribution of G. lailad and $G$. amarpur is probably restricted to small areas in northeast India, as Bhowmik (1986) does not list any Genimen species in his comprehensive treatment of the grasshopper fauna of West Bengal.

The genus Apalniacris is at the present state of knowledge endemic to northeastern India. The four species included are squamipterous and unable to fly. One might thus expect that their ranges are small. However, it is not unlikely that additional species may occur in the neighbouring areas of China and Myanmar.

\section{REFERENCES}

Balderson, J. \& Yin X., 1987. Grasshoppers (Orthoptera: Tetrigoidea and Acridoidea) collected in Nepal. - Entomologist's Gazette 38: 269-299.

Bhowmik, H. K., 1985. Outline of distribution with an index catalogue of Indian grasshoppers (Orthoptera: Acridoidea). Part I. Subfamilies: Acridinae, Truxalinae, Gomphocerinae and Oedipodinae. - Records of the Zoological Survey of India, Miscellaneous Publication, Occasional Paper 78: 1-51.

Bhowmik, H. K., 1986. Grasshopper fauna of West Bengal, India (Orthoptera: Acrididae). - Zoological Survey of India Technical Monograph 14: 1-192.

Bhowmik, H. K., 1993. On the biogeographical regions of India in relation to studies in the endemism of Acrididae fauna of India. - Records of the Zoological Survey of India Occasional Paper 131: 1-56.

Bhowmik, H. K., B. C. Saha \& R. N. Bhargava, 1990. Contribution to the acridid fauna (Orthoptera) of north-eastern states of India. - Records of the Zoological Survey of India 86: 217-227.

Dirsh, V. M., 1956. The phallic complex in Acridoidea (Orthoptera) in relation to taxonomy. - Transactions of the Royal Entomological Society of London 108: 223-356, pls 1-66.
Eades, D. C., 1961. The terminology of phallic structures in the Cyrtacanthacridinae (Orthoptera, Acrididae). - Entomological News 72: 141-149.

Hazra, A. K., S. K. Tandon, M. S. Shishodia, S. K. Mondal \& A. Dey, 1995. Insecta: Orthoptera: Acridoidea. - State Fauna Series 4 Fauna of Meghalaya 3 Insecta: 209-277.

Hollis, D., 1971. A preliminary revision of the genus Oxya Audinet-Serville (Orthoptera: Acridoidea). - Bulletin of the British Museum (Natural History), Entomology Series 26: 267-343.

Hollis, D., 1975. A review of the subfamily Oxyinae (Orthoptera: Acridoidea). - Bulletin of the British Museum (Natural History), Entomology Series 31: 189-234.

Huang C., 1981. Orthoptera: Acrididae - Catantopinae, Pyrgomorphinae, Oedipodinae - Insects of Xizang 1: 6386, pls 1-3. [In Chinese with English summary.]

Huang C., 1983. New genus and new species of Acrididae from Yunnan. - Zoological Research 4: 147-150; Kunming. [In Chinese with English summary.]

Ingrisch, S., 1989. Records, descriptions, and revisionary studies of Acrididae from Thailand and adjacent regions (Orthoptera, Acridoidea). - Spixiana 11: 205-242.

Kirby, W. F., 1914. Orthoptera, 1 (Accididae) [sic]. - In: Bingham [ed.]. The Fauna of British India including Ceylon and Burma. - New Delhi. i-x, 1-276.

Ma E. \& Zheng Z., 1994. A new species of Lemba from Yunnan, China (Orthoptera, Catantopidae). - Acta Zootaxonomica Sinica 19: 187-189. [In Chinese with English summary.]

Ma E., Guo Y, \& Li C., 1994. The genus Lemba (Orthoptera: Acridoidea) with description of a new species from China. - Oriental Insects 28: 97-101.

Mishchenko, L.L. 1952. Orthoptera 4 (2). Locusts and Grasshoppers Catantopinae. - Fauna of the U.S.S.R. Moscow: i-xiii, 1-560 [In Russian; English translation Jerusalem 1965].

Mondal, S. K., A. K. Hazra \& S. K. Tandon, 1999. Studies on taxonomy, biology and ecology of grasshoppers infesting field crops and vegetables with notes on nymphal taxonomy of some species in West Bengal. - Records of the Zoological Survey of India Occasional Paper 173: 1-178.

Niu Y. \& Zheng Z., 1992. A new species of Lemba Huang from Yunnan, China (Orthoptera: Catantopidae). Journal of Henan Normal University (Natural Science) 20 (3) [76]: 76-78. [In Chinese with English summary.]

Otte, D., D. C. Eades \& P. Naskrecki, 2004. Orthoptera Species File Online - http://osf2x.orthoptera.org/osf2.2/ OSF2XFrameset.htm (visited 1.x.2004).

Ramme, W., 1941. Beiträge zur Kenntnis der AcrididenFauna des indomalayischen und benachbarter Gebiete (Orth.) mit besonderer Berücksichtigung der Tiergeographie von Celebes. - Mitteilungen aus dem Zoologischen Museum, Berlin 25: 1-243, pls 1-21.

Tandon, S. K., 1976. A check-list of the Acridoidea (Orthoptera) of India Part I Acrididae. - Records of the Zoological Survey of India, Miscellaneous Publication, Occasional Paper 3: 1-48.

Tandon, S. K., 1988. Distributional pattern of grasshoppers of India: the distribution of Oxyinae (Orthoptera: Acridoidea: Acrididae) in Indian region. - Records of the Zoological Survey of India 85: 101-110.

Tinkham, E. R., 1940. Taxonomic and biologicial studies of the Cyrtacanthacrinae of South China. - Lingnan Science Journal 19: 269-382, pls 10-16.

Usmani, M.K. \& S.A. Shafee, 1985. A revision of the Indi- 
an species of Oxya (Acrididae: Oxyinae). - Oriental Insects 19: 311-322.

Uvarov, B. P., 1942. New Acrididae from India and Burma. - Annals and Magazine of Natural History (33) 9: 587 607.

Willemse, C., 1931. Orthoptera Celebica Sarasiniana. I. Saltatoria, Fam. Acrididae. - Treubia 12 (supplement): 189-273.

Willemse, C., 1956. Synopsis of the Acridoidea of the IndoMalayan and adjacent regions (Insecta, Orthoptera). Part II. Fam. Acrididae, subfam. Catantopinae, part one. Publicaties van het Natuurhistorisch Genootschap in Limburg 8: 1-226.

Willemse, C., 1957. Synopsis of the Acridoidea of the IndoMalayan and adjacent regions (Insecta, Orthoptera). Part II. Fam. Acrididae, subfam. Catantopinae, part II. - Publicaties van het Natuurhistorisch Genootschap in Limburg 10: 227-500, i-v, pls 1-15.

Willemse, F., 1965. Orthoptera, Acridoidea chiefly from Java in the Zoologisches Staatsinstitut und Zoologisches Museum of Hamburg. - Entomologische Mitteilungen aus dem Zoologischen Staatsinstitut und Zoologischen Museum Hamburg 3: 53-67.

Yin X. \& Liu Z., 1987. A new subfamily of Catantopidae with a new genus and new species from China (Orthoptera: Acridoidea). - Acta Zootaxonomica Sinica 12: 66-72. [In Chinese with English summary.]

Yin, X., 1984. Grasshoppers and locusts from QinghaiXizang Plateau of China. - Northwest Plateau Institute of Biology, Academia Sinica, Xining, \& Science Press, Beijing. 1-287, pls 1-34. [In Chinese with English summary.]

Zheng Z., 1981. New genera and new species of grasshoppers from Yunnan, Guizhou and Sichuan, China. - Acta Zootaxonomica Sinica 6: 60-68. [In Chinese with English summary.]

Zheng Z., Huang Q. \& Liu Z., 1988. A new species and a new record of grasshoppers from Yunnan (Orthoptera: Catantopidae). - Entomotaxonomia 10: 83-86. [In Chinese with English summary.]

Received: 29 April 2004

Accepted: 23 September 2004

\section{Abbreviations as used in figures}

an - anchora of epiphallus

ap - apodeme of cingulus

$\mathrm{br}$ - bridge of epiphallus

bv - basisvalvula of ovipositor

ce - cercus

ci - cingulus

$\mathrm{da}$ - dorsal aedeagal valves

ds - dorsal aedeagal sclerite

$\mathrm{dv}$ - dorsal valves of ovipositor

e - supra-anal plate

ej - ejaculatory duct

ep - endophallic plate

esd - dorsal sclerite of ectophallic membrane

esv - ventral sclerite of ectophallic membrane

$\mathrm{f}$ - furcula

i - internal membranes after extraction of phallus

lo - lophus of epiphallus

ls - lateral sclerite of epiphallus

ms - mesosternum

$\mathrm{mt}$ - metasternum

pa - paraproct

ps - prosternum

ra - ramus

sg - subgenital plate

sh - membranous sheath

$\mathrm{tt}$ - terminal tergite

va - ventral aedeagal valves

$\mathrm{vv}$ - ventral valves of ovipositor 

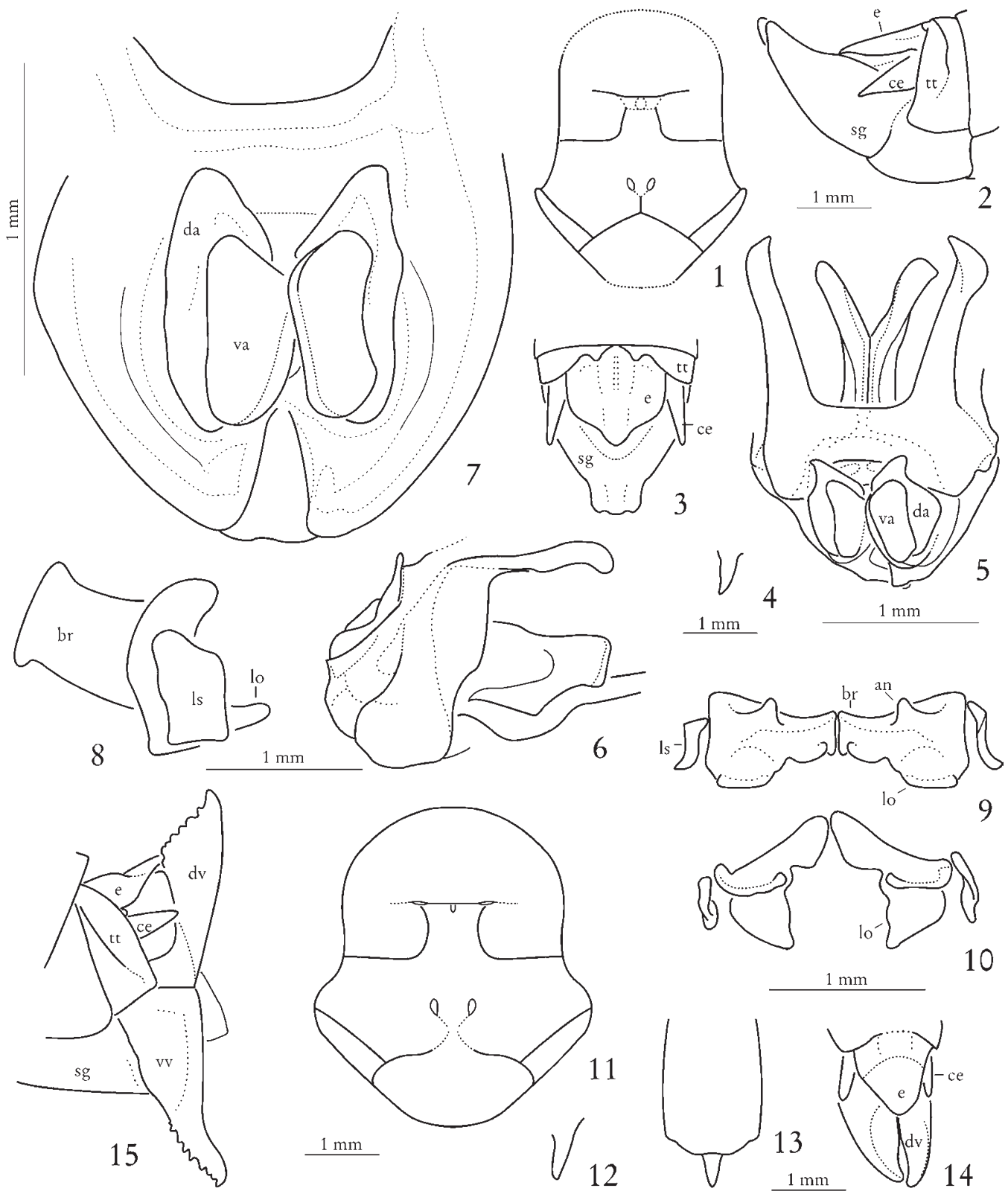

9

12
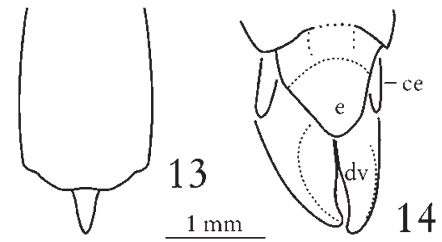

Figs. 1-15. Lemba motinagar sp. n. male (1-10) and female (11-15), details of morphology and genitals. - 1, 11, Thoracic sternites; 2,15 , abdominal apex in lateral view; 3,14 , same in dorsal view; 4, 12, prosternal spine in lateral view; 5-7, phallic complex in dorsal view (5), lateral view (6) and dorsal-apical view (7); 8-10, epiphallus in lateral view (8), dorsal view (9) and view on the lophi (10); 13, subgenital plate. 


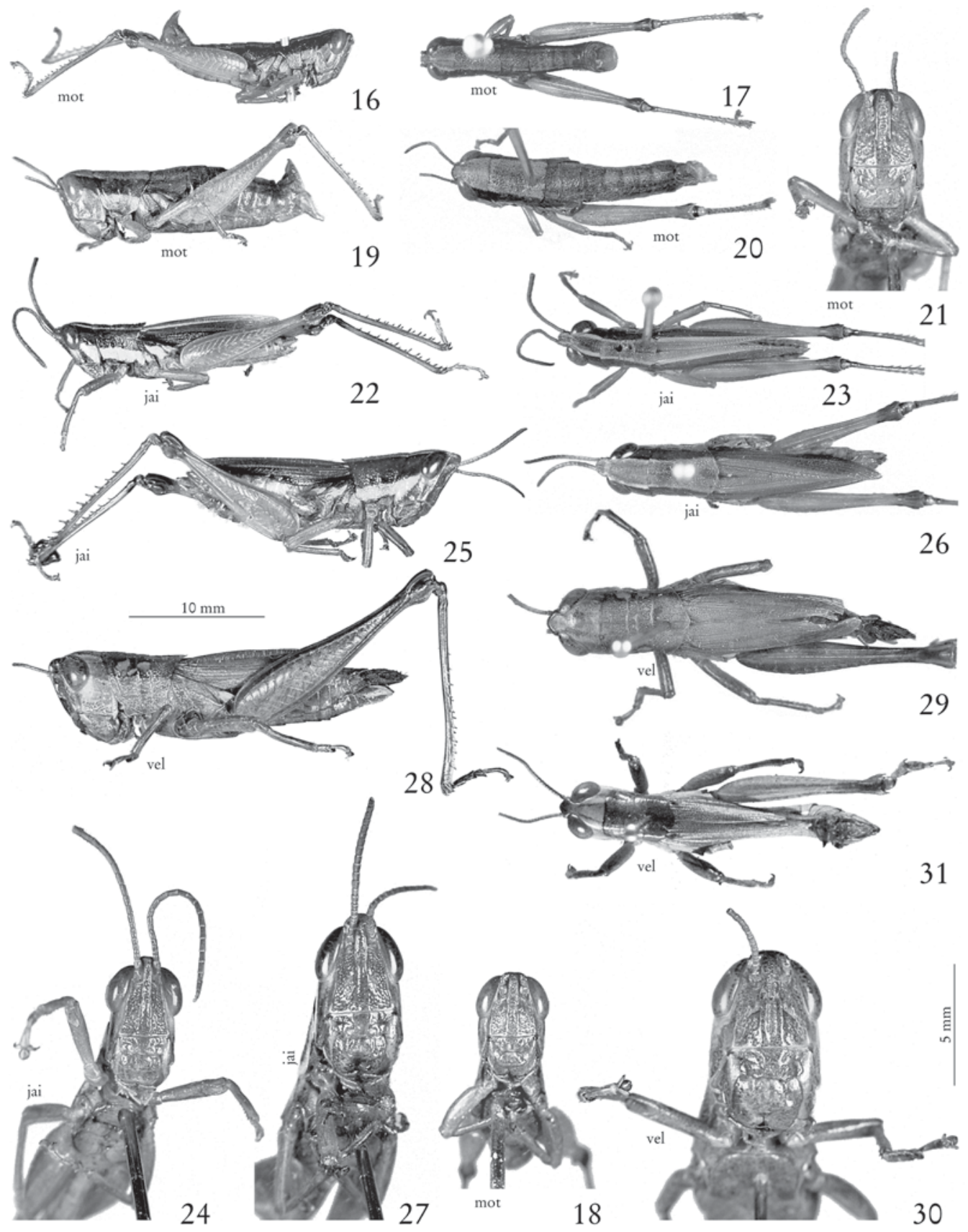

Figs. 16-31. Habitus lateral view (16, 19, 22, 25, 28), habitus dorsal view (17, 20, 23, 26, 29, 31) and frons (18, 21, 24, 27, 30). - 16-18, Lemba motinagar sp. n. male (holotype); 19-21, L. motinagar sp. n. female (paratype); 22-24, Oxytauchira jaintia sp. n. male (holotype); 25-27, O. jaintia sp. n. female (paratype); 28-30, Oxya velox (Fabricius, 1787) var. female; $31, O$. velox var. male. 


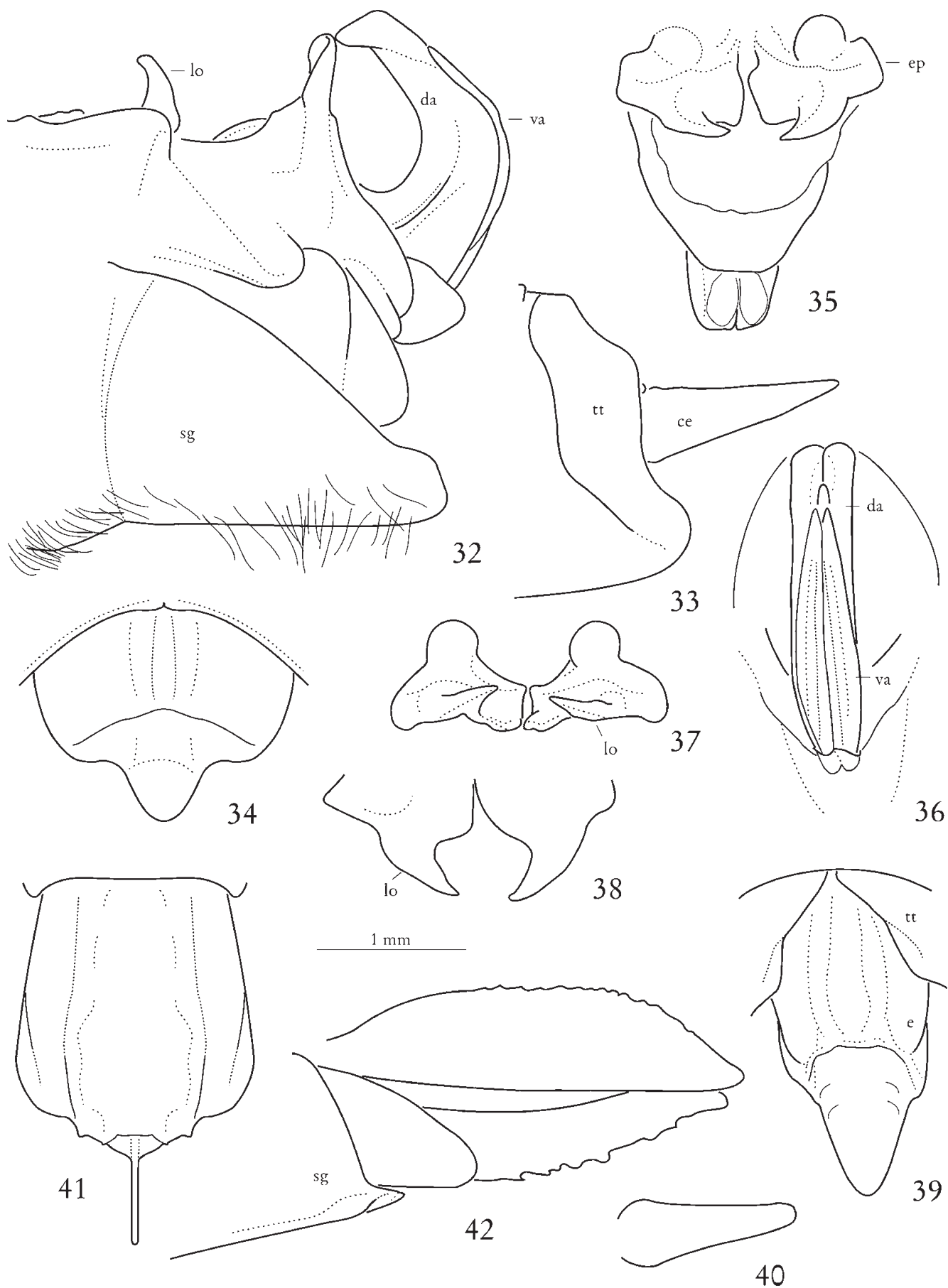

Figs. 32-42. Oxya velox (Fabricius, 1787) var. male (32-38) and female (39-42), details of morphology and genitals. - 32, Abdominal apex in lateral view with phallus extruded; 33, terminal tergite and cercus in lateral view; 34, 39, supra-anal plate; 35 , phallic complex in dorsal view with epiphallus; 36, phallic complex in ventro-apical view; 37-38, epiphallus in apical view (37) and ventral view on lophi (38); 40, cercus; 41, subgenital plate; 42, ovipositor. 


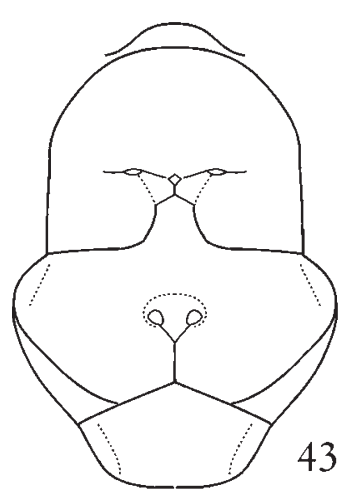

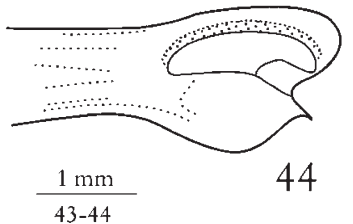

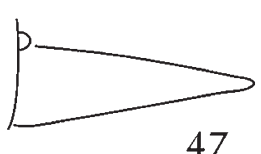

47

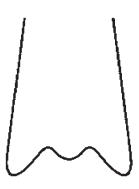

46

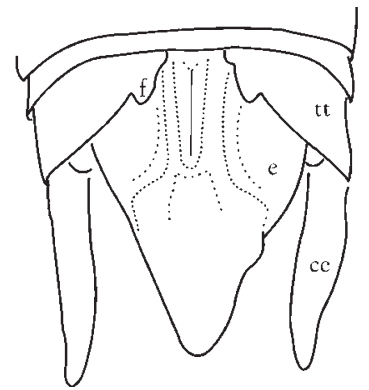

45
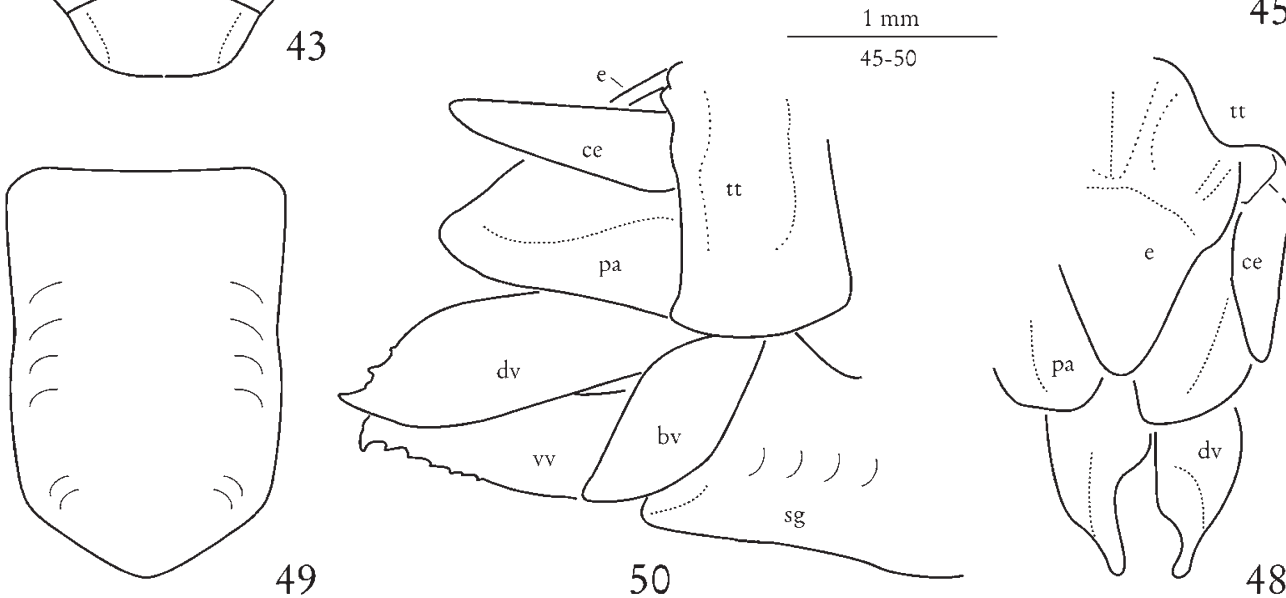

Figs. 43-50. Oxytauchira jaintia sp. n. male (43-47) and female (48-50), details of morphology. - 43, Thoracic sternites; 44, apex of left hindfemur in external view; 45, 48, apex of abdomen (basal-left part of 48 hidden by wings); 46, prosternal spine from behind; 47, left cercus in lateral view; 49, subgenital plate; 50, apex of abdomen with ovipositor.
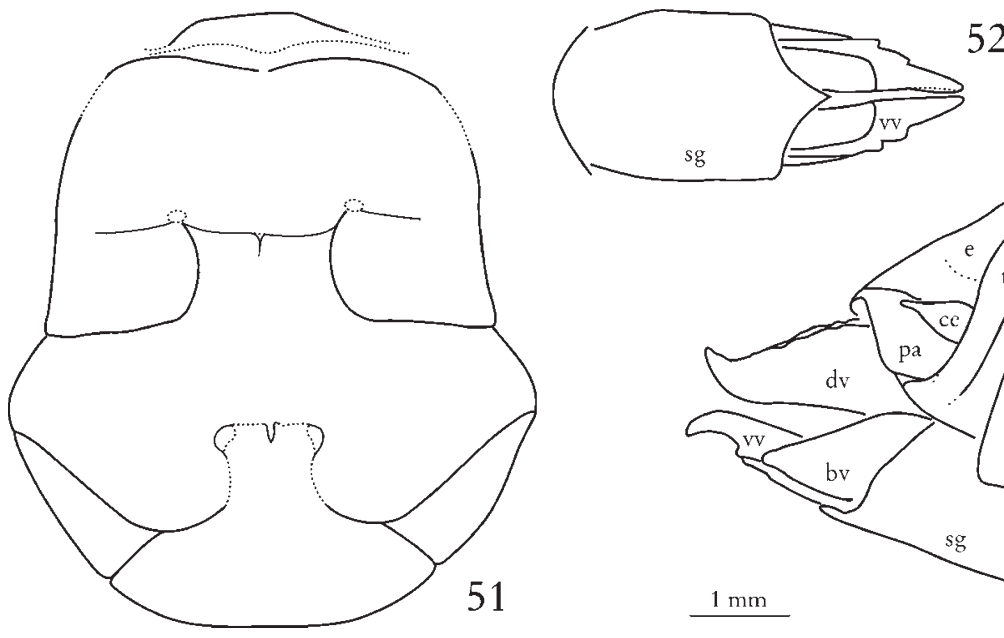

52

Figs. 51-53. Eucoptacra abbreviata sp. n. female, details of morphology. - 51, Thoracic sternites; 52, subgenital plate and ovipositor in ventral view; 53, abdominal apex in lateral view. 

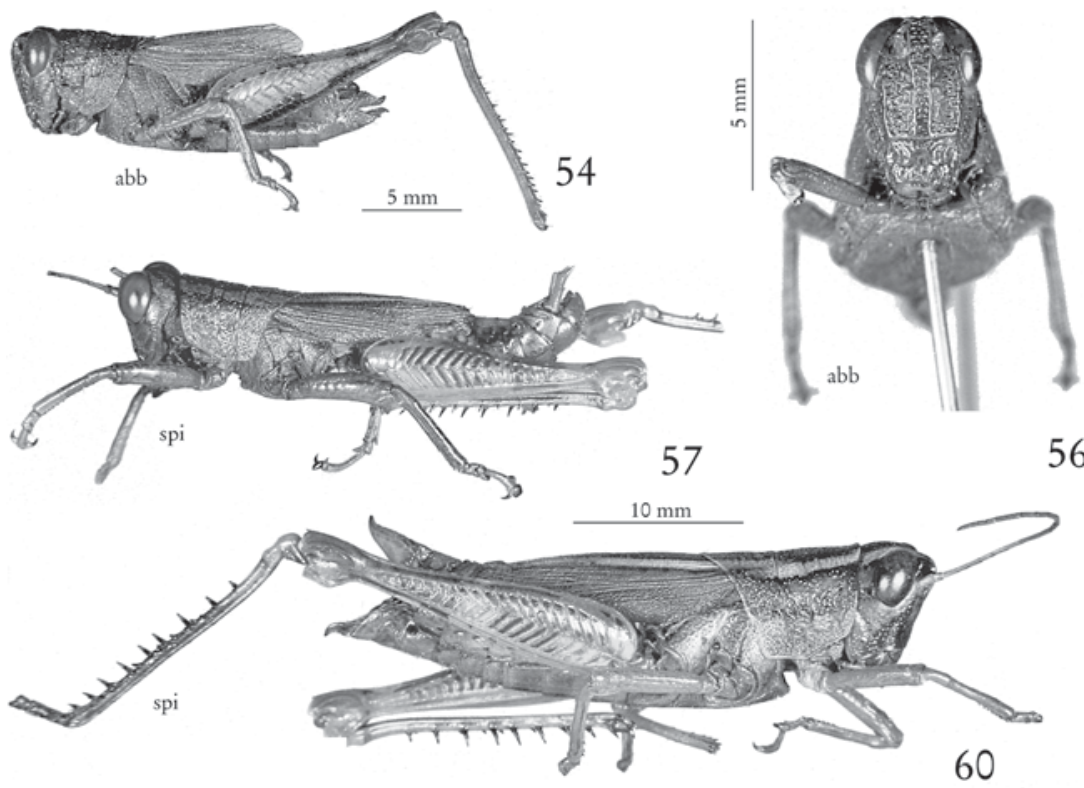

56
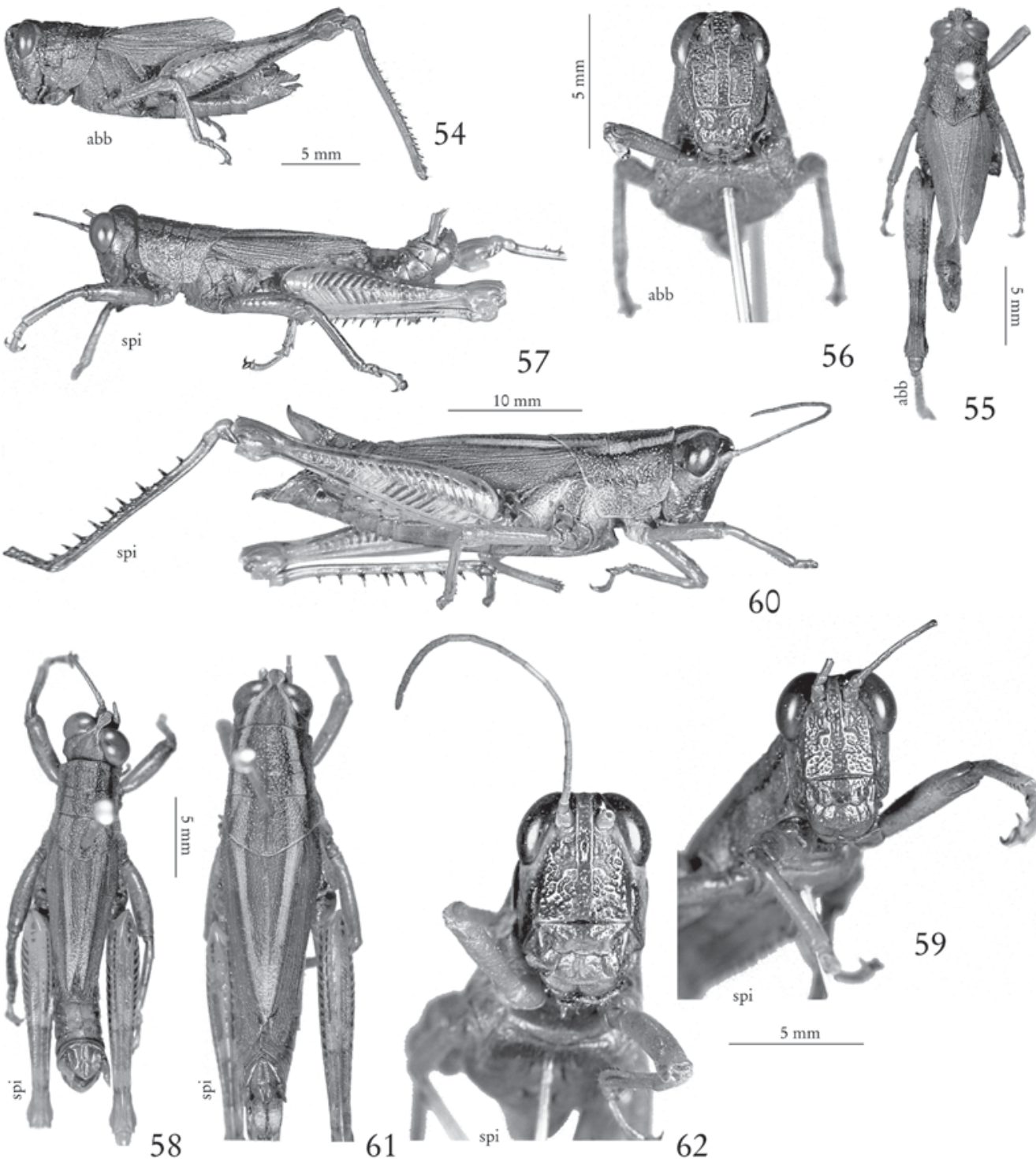

Figs. 54-62. Habitus lateral view $(54,57,60)$, habitus dorsal view $(55,58,61)$ and frons $(56,59,62)$. - 54-56, Eucoptacra abbreviata sp. n. female (holotype); 57-59, Assamacris spinipicta sp. n. male (holotype); 60-62, Assamacris spinipicta sp. n. female (paratype). 


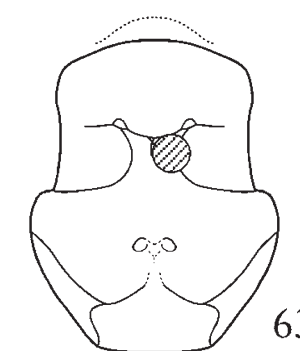

$$
1 \mathrm{~mm}
$$
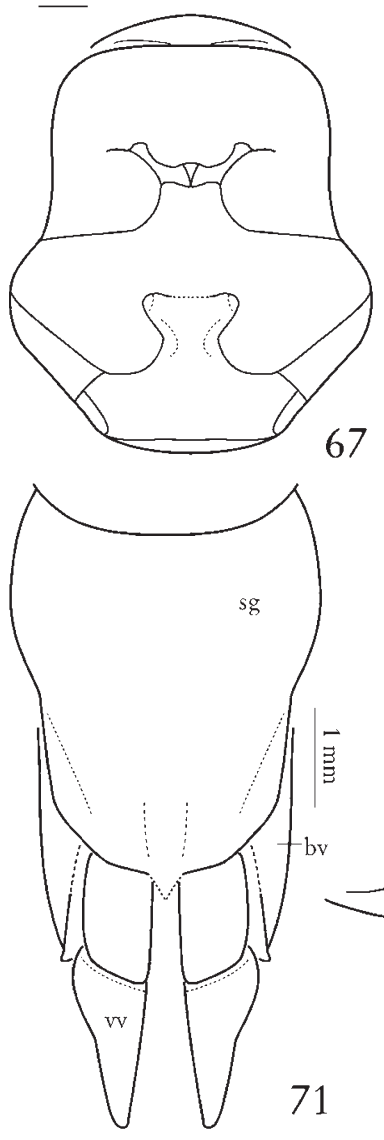
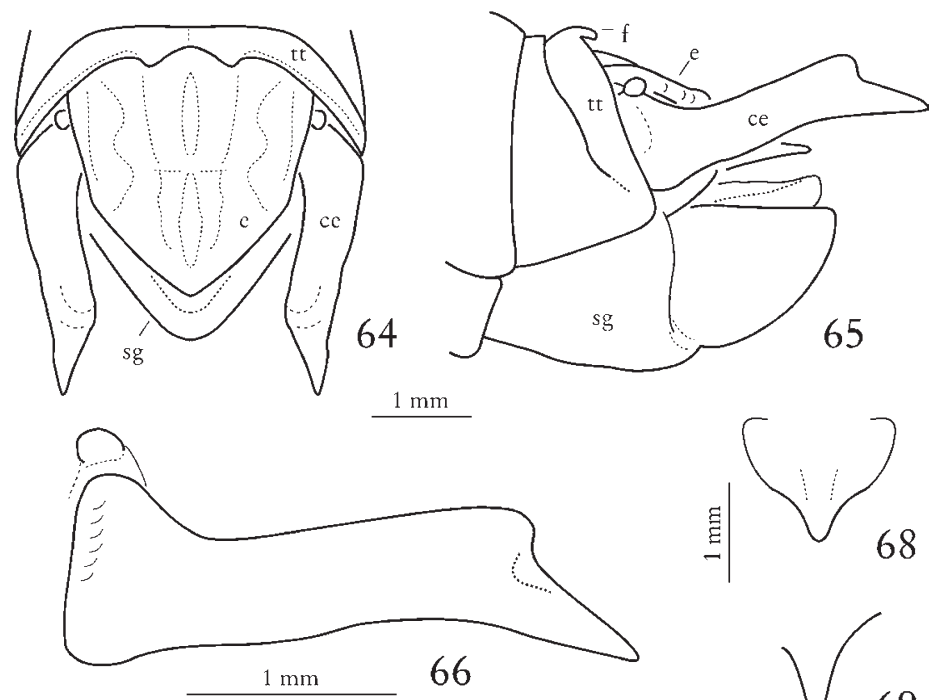

68

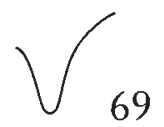

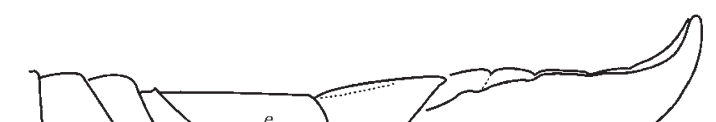
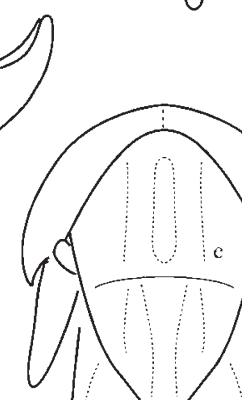

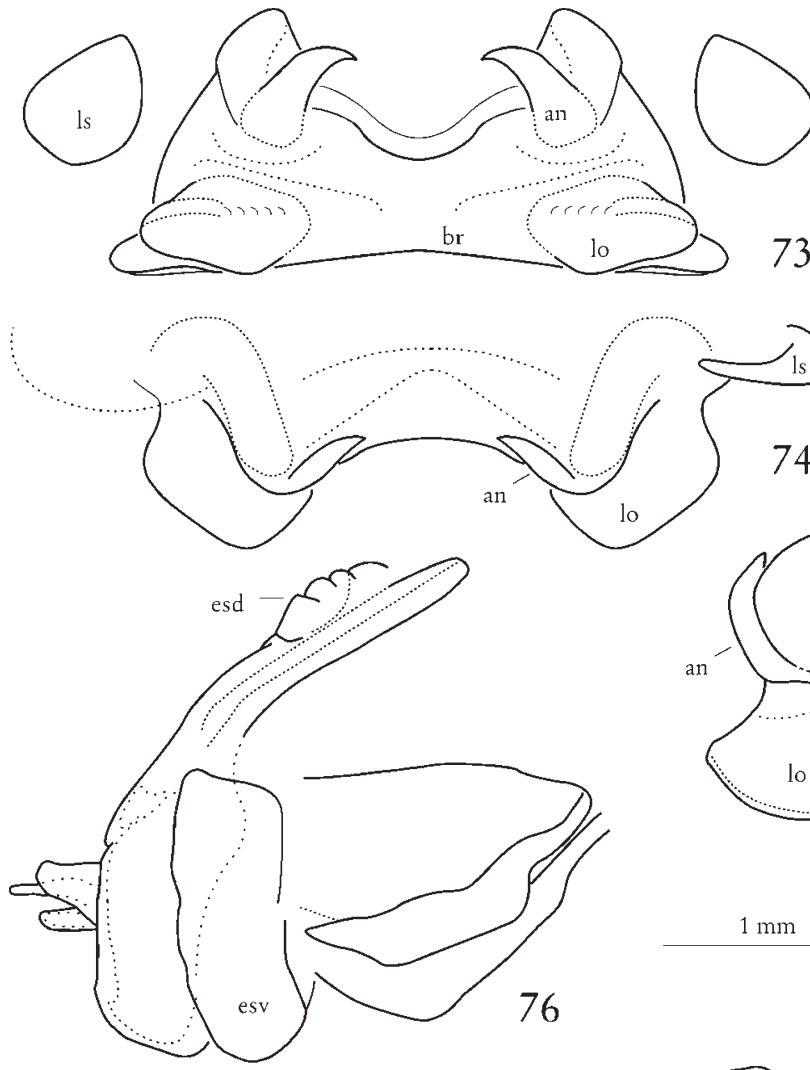

73
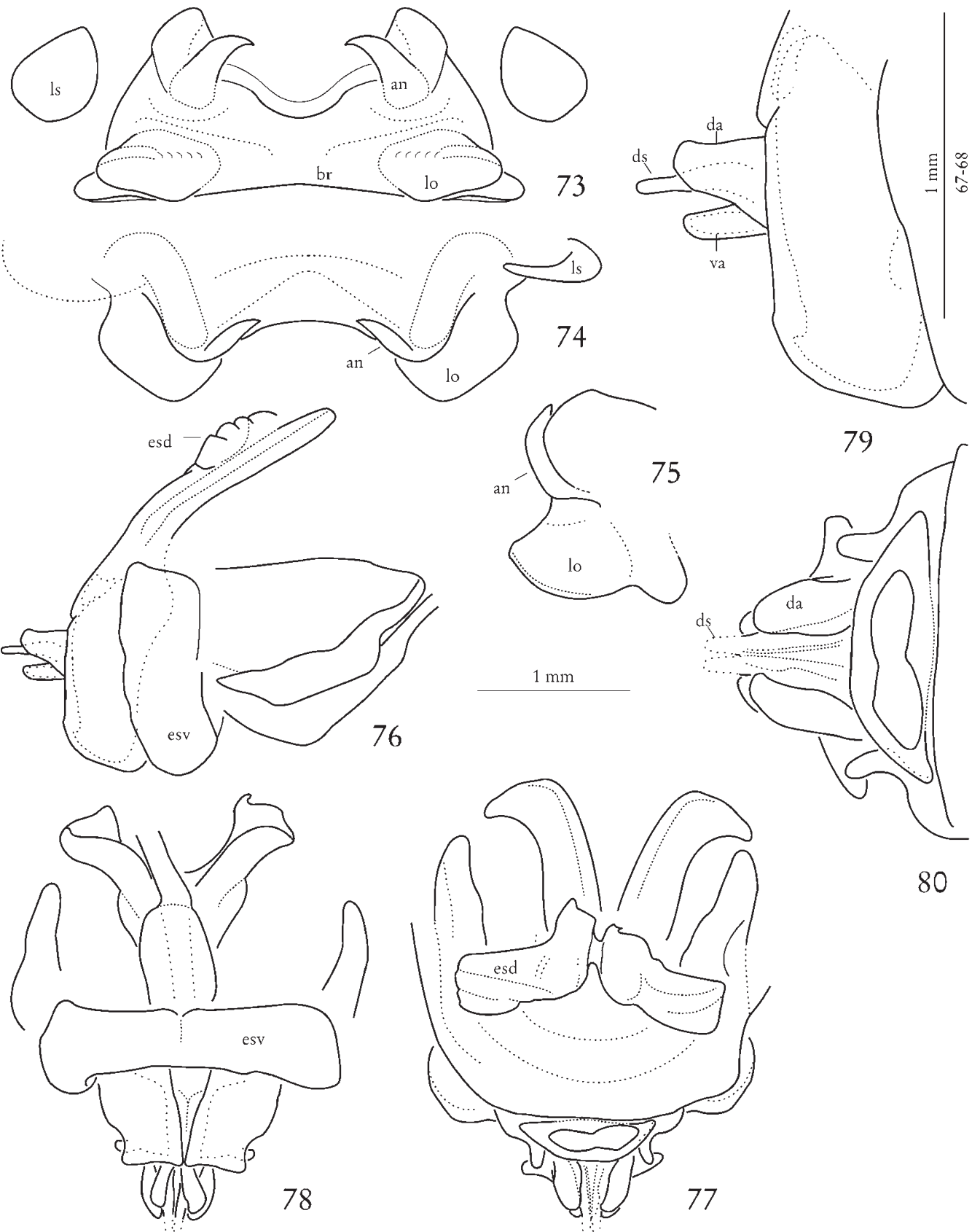

Figs. 73-80. Assamacris spinipicta sp. n. male phallic complex. - 73-75, Epiphallus in dorsal view (73), anterior view (74) and lateral view (75); 76-78, phallic complex in lateral view (76), dorsal view (77) and ventral view (78); apex of phallic complex in lateral view (79) and dorsal view (80). Styliform projection of dorsal aedeagal sclerite broken, its situation reconstructed from separately conserved remnant (stippled line). 


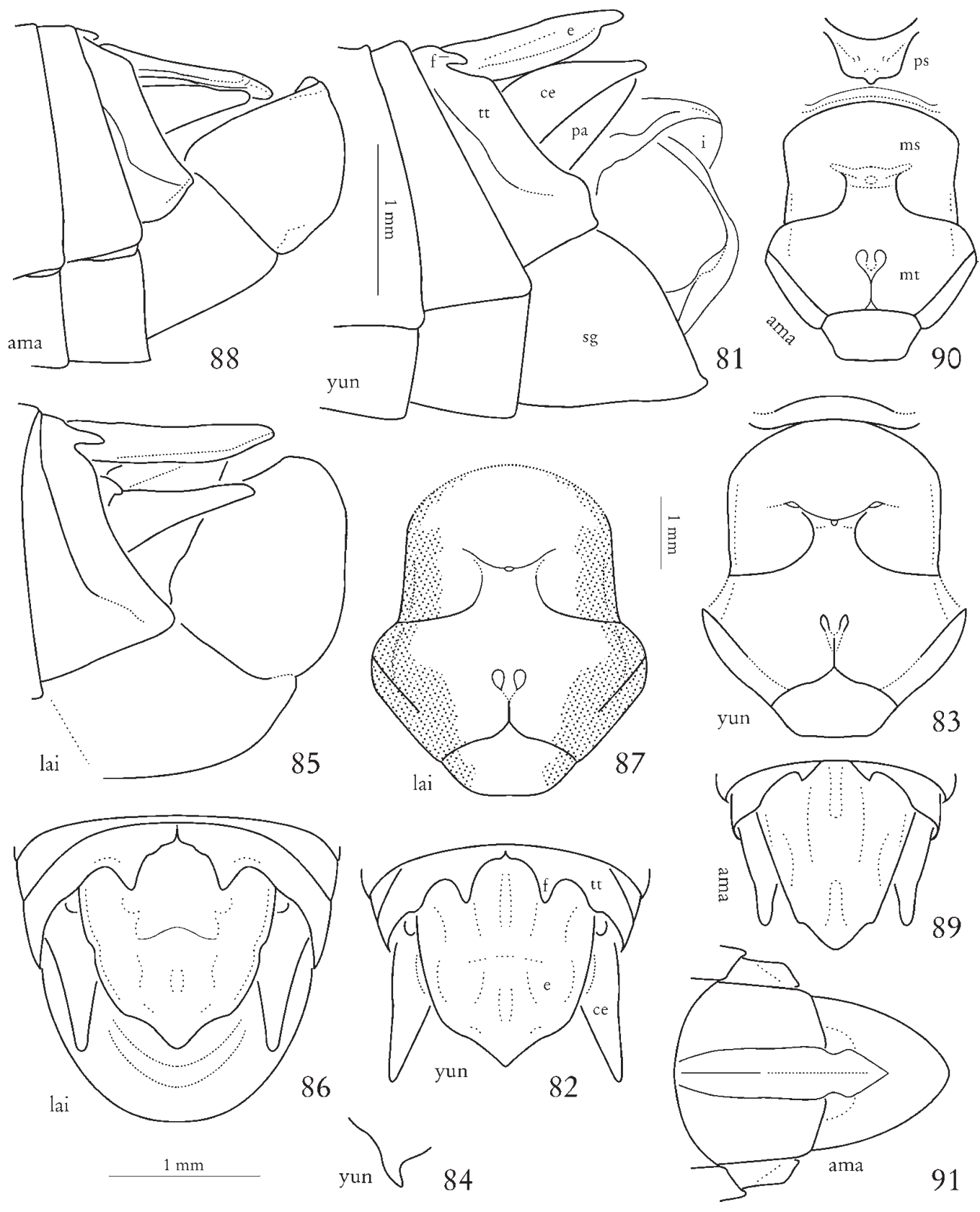

Figs. 81-91. Genimen species from NE India, details of male morphology. - 81-84, ? G. yunnanensis Zheng et al., 1988; 8587, G. lailad sp. n.; 88-91, G. amarpur sp. n.: 81, 85, 88, abdominal apex in lateral view; 82, 86, 89, same in dorsal view; 83, 87,90 , thoracic sternites; 84 , prosternal spine in lateral view; 91 , subgenital plate in ventral view. 

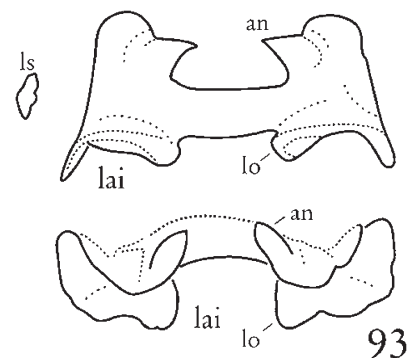

92

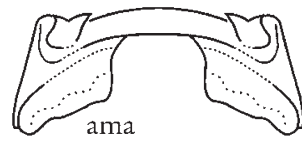

99

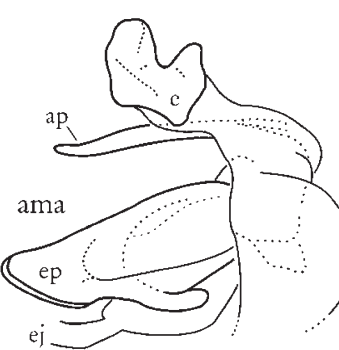

93

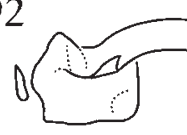

ama

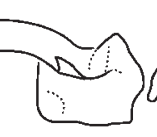

$1 \mathrm{~mm}$

100

lai

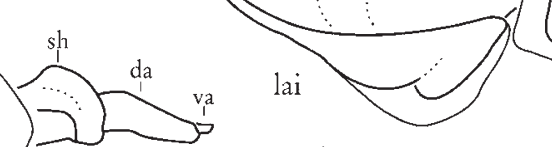

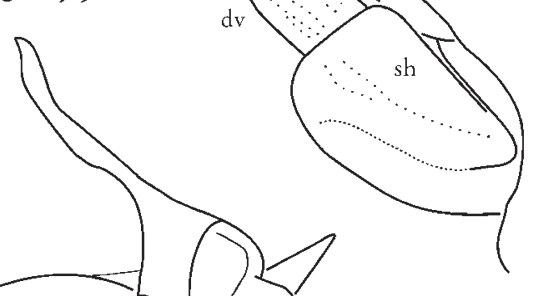
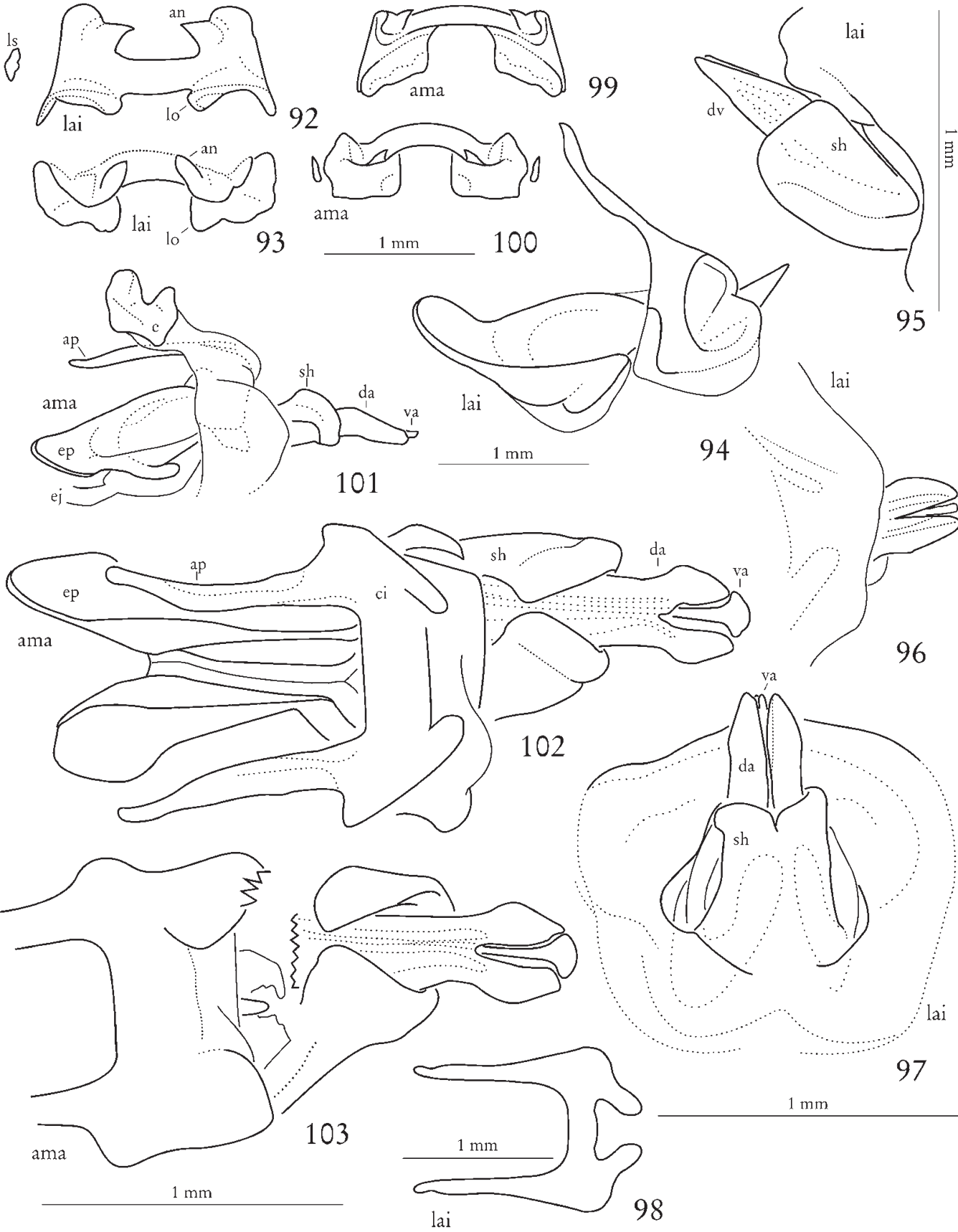

Figs. 92-103. Genimen species from NE India, details of male phallic complex. -92-98, G. lailadsp. n.; 99-103, G. amarpur sp. n.: 92, 99, epiphallus in dorsal view (lateral sclerites of ephiphallus not always drawn); 93, 100, same in anterior view on lophi; 94, 101, phallic complex in lateral view (101 including epiphallus); 95, apex of phallus in lateral view; 96, same in dorsal view; 97, same in ventro-apical view; 98, cingulum; 102, phallic complex in dorsal view; 103, apical part of phallic complex in ventral view (zigzag lines $=$ preparation broken). 


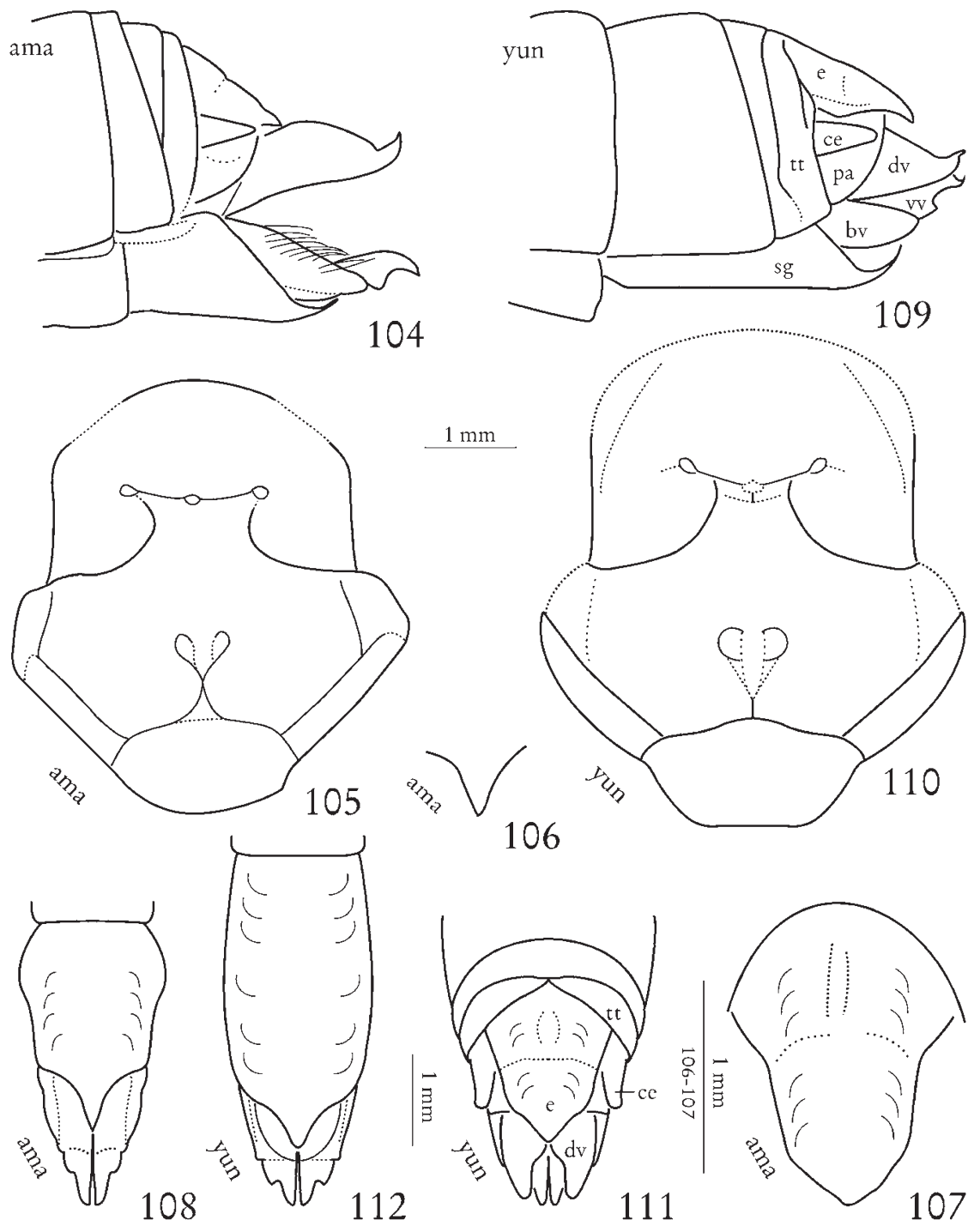

Figs. 104-112. Genimen species from NE India, details of female morphology. - 104-108, G. amarpur sp. n.; 109-112, ? G. yunnanensis Zheng et al. 1988: 104, 109, abdominal apex in lateral view; 105, 110, thoracic sternites; 106, prosternal spine in lateral view; 107, supra-anal plate; 108, 112, subgenital plate and ovipositor in ventral view; 111, abdominal apex in dorsal view. 


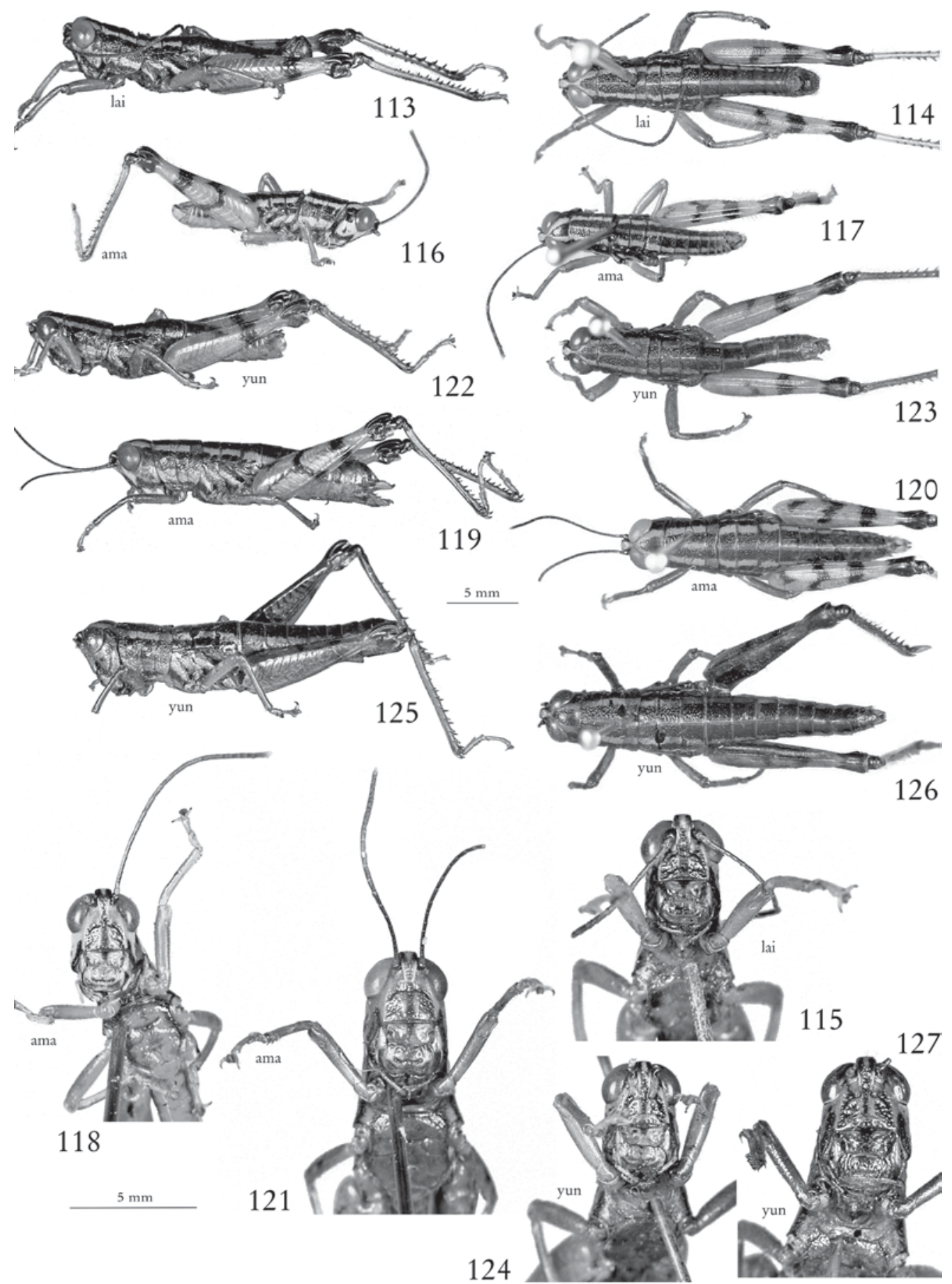

Figs. 113-127. Habitus lateral view $(113,116,119,122,125)$, habitus dorsal view $(114,117,120,123,126)$ and frons (115, $118,121,124,127)$ of Genimen species from NE India. - 113-115, G. lailad sp. n. male (holotype); 116-118, G. amarpur sp. n. male (holotype); 119-121, G. amarpursp. n. female (paratype); 122-124, ? G. yunnanensis Zheng et al. 1988 male from Moreh; 125-127, same, female. 

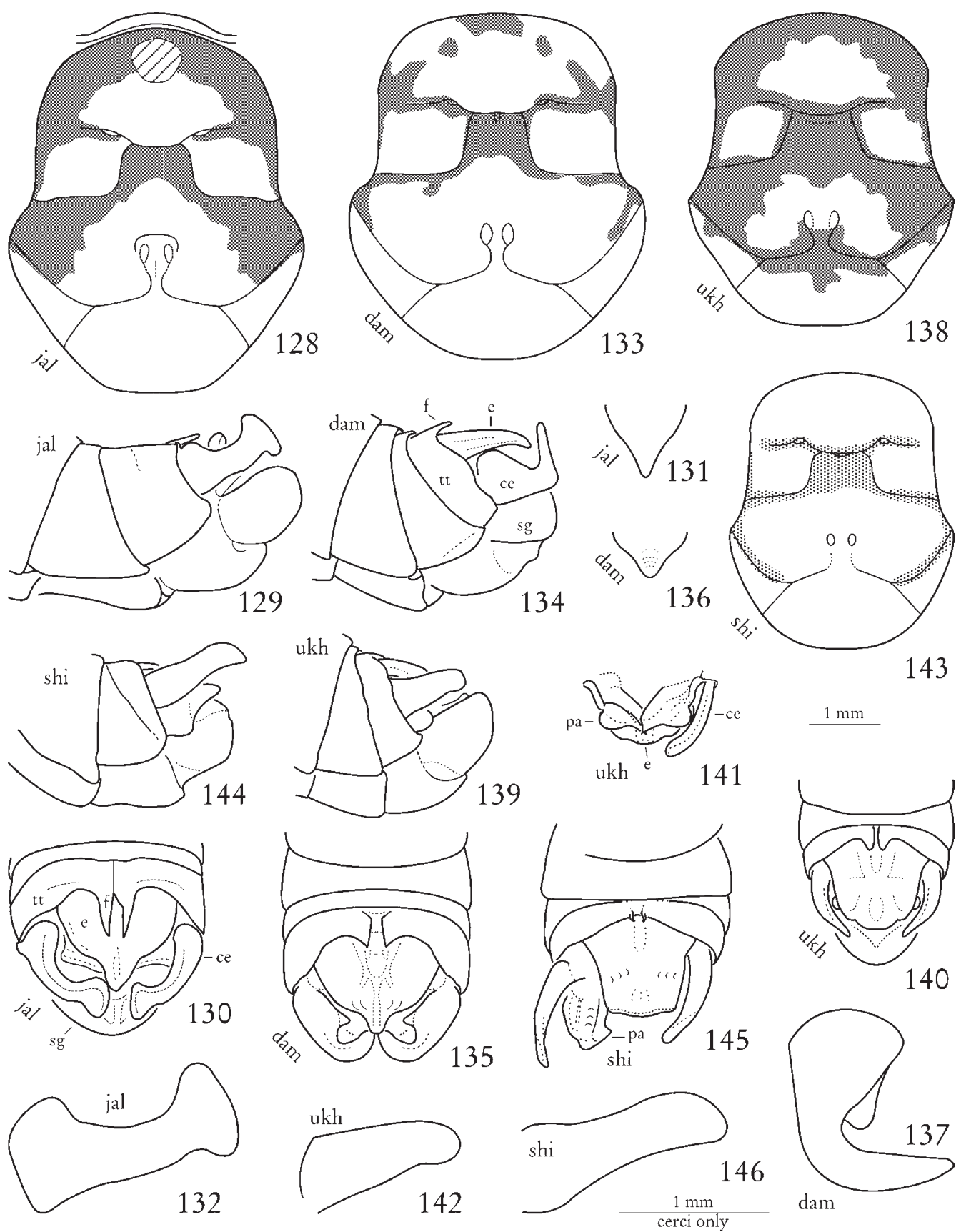

Figs. 128-146. Apalniacris species from NE India, details of male morphology. - 128-132, A. jalpaiguri sp. n.; 133-137, A. dampha sp. n.; 138-142, A. ukhrulsp. n.; 143-146, A. shillong sp. n.: 128, 133, 138, 143, thoracic sternites; 129, 134, 139, 144, abdominal apex in lateral view; $130,135,140,145$, same in dorsal view; 131, 136, prosternal spine in anterior view; $132,142,146$, left cercus in lateral view; 137 , same in dorsal view; 141, paraprocts, apex of supra-anal plate and left cercus in ventral view. 

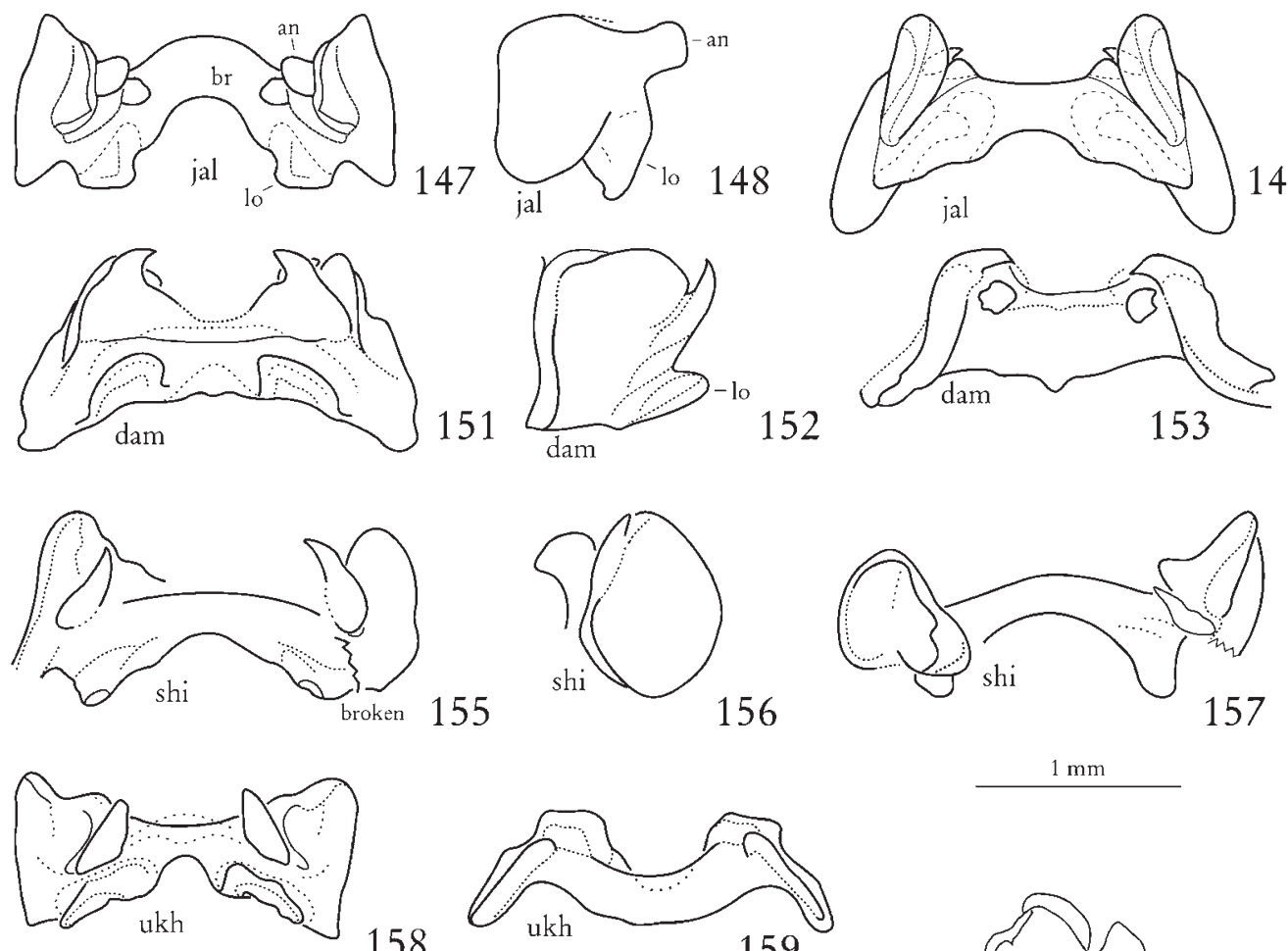

158
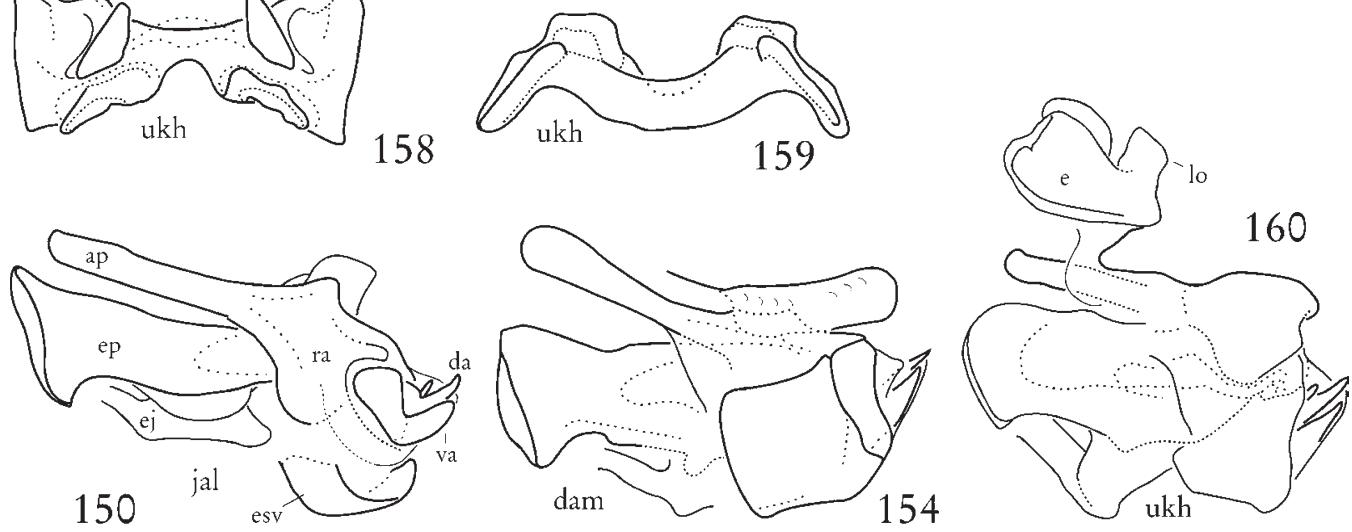

Figs. 147-160. Apalniacris species from NE India, details of male phallic complex. - 147-150, A. jalpaiguri sp. n.; 151-154, A. dampha sp. n.; 155-157, A. shillong sp. n.; 158-160, A. ukhrul sp. n.: 147, 151, 155, 158, epiphallus in dorsal view; 148 , 152,156 , same in lateral view; $149,153,157,159$, same in anterior view; 150, 154, 160, phallic complex in lateral view (160 including epiphallus) 

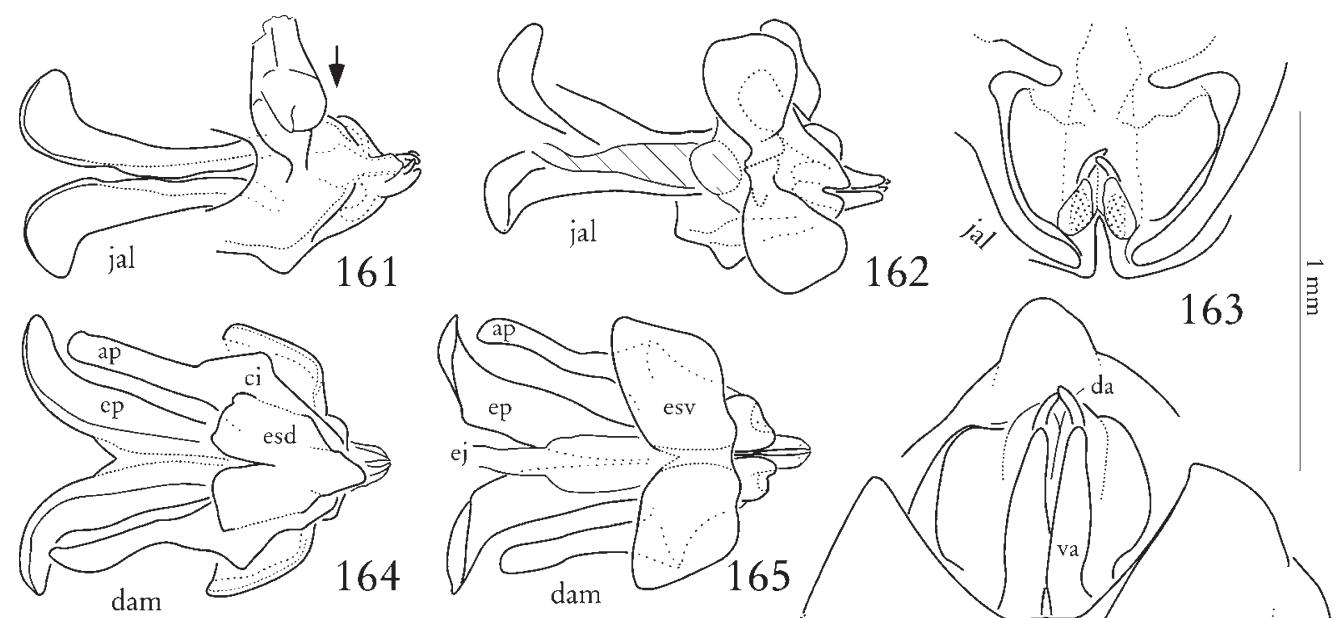

163

dam
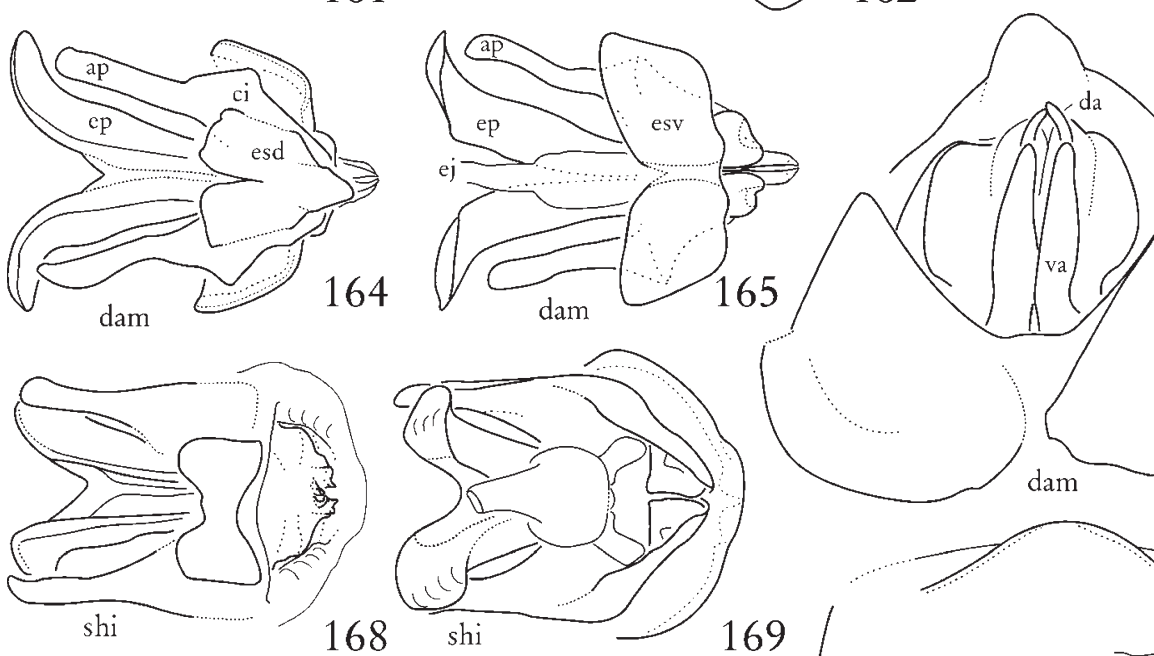

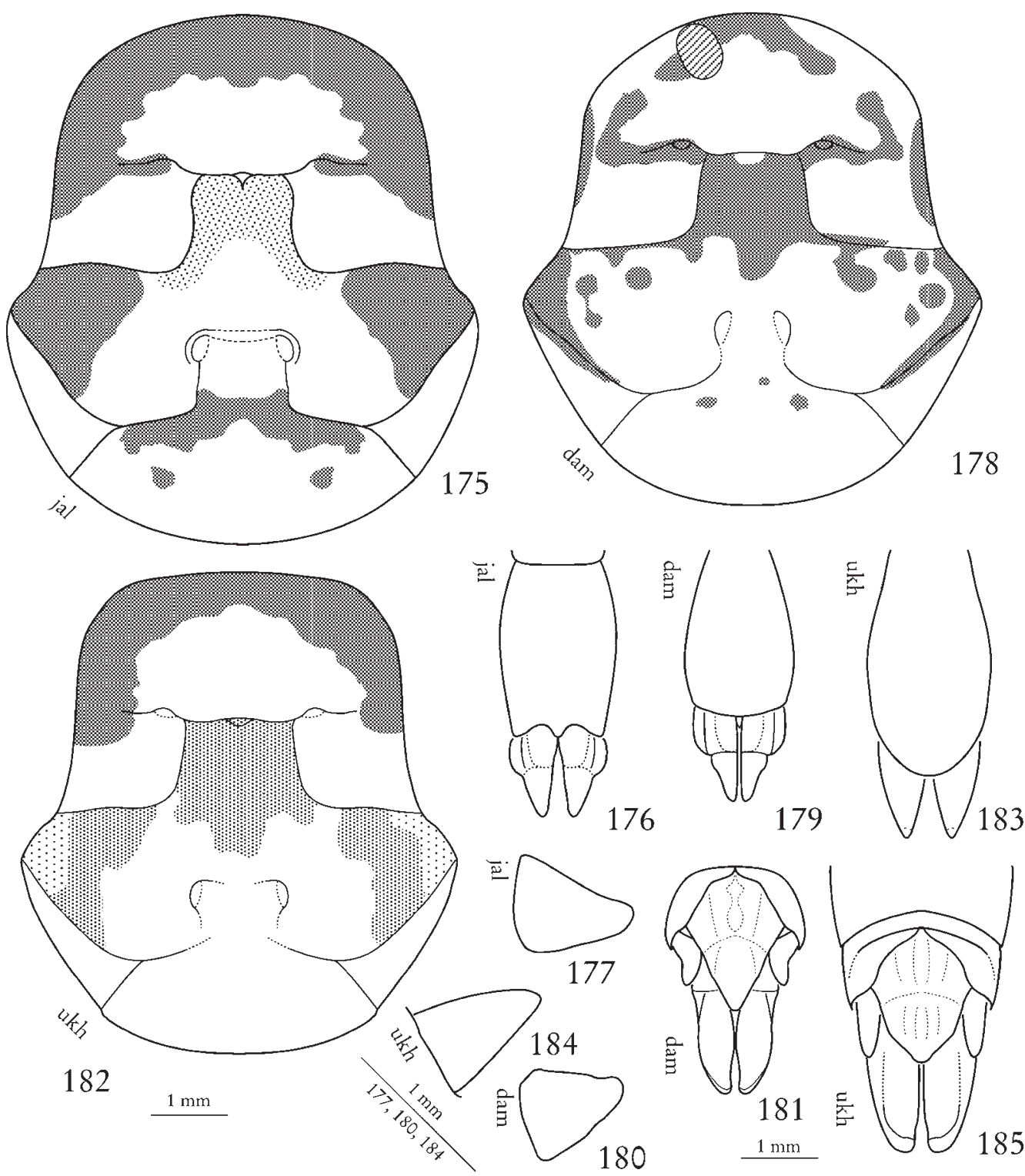

Figs. 175-185. Apalniacris species from NE India, details of female morphology. - 175-177, A. jalpaiguri sp. n.; 178-181, A. dampha sp. n.; 182-185, A. ukhrulsp. n.: 175, 178, 182, thoracic sternites; 176, 179, 183, subgenital plate and ovipositor in ventral view; $177,180,184$, left cercus in lateral view; 181, 185, abdominal apex in dorsal view. 

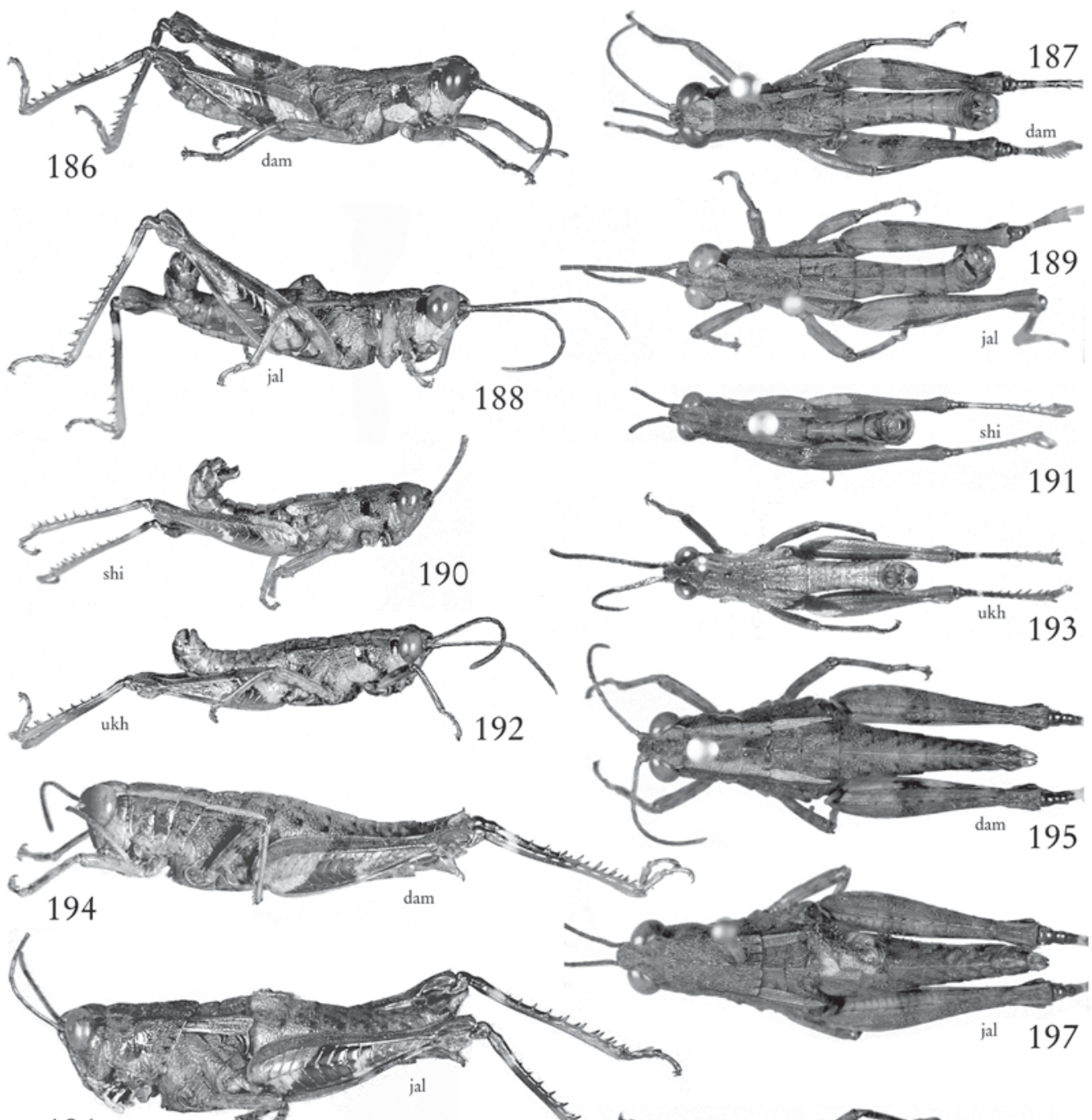

196

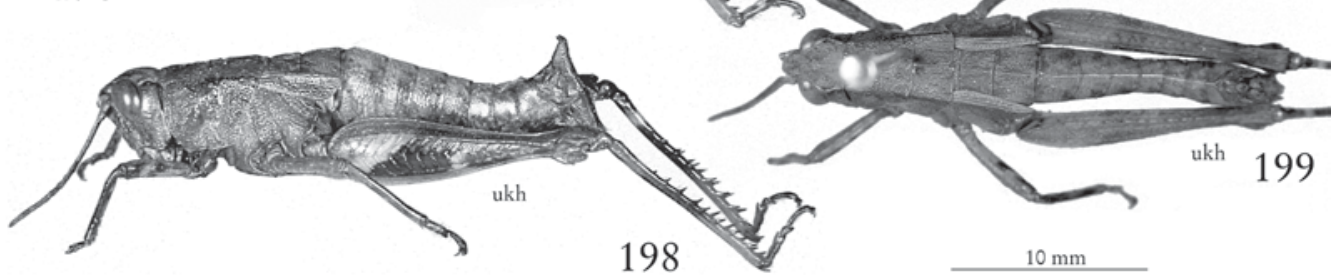

Figs. 186-199. Habitus lateral view $(186,188,190,192,194,196,198)$ and habitus dorsal view $(187,189,191,193,195$, 197, 199) of Apalniacris species from NE India. - 186-187, A. dampha sp. n. male (holotype); 188-189, A. jalpaiguri sp. n. male (holotype); 190-191, A. shillong sp. n. male (holotype); 192-193, A. ukhrulsp. n. male (holotype); 194-195, A. dampha sp. n. female (paratype); 196-197, A. jalpaiguri sp. n. female (paratype); 198-199, A. ukhrulsp. n. female (paratype). 

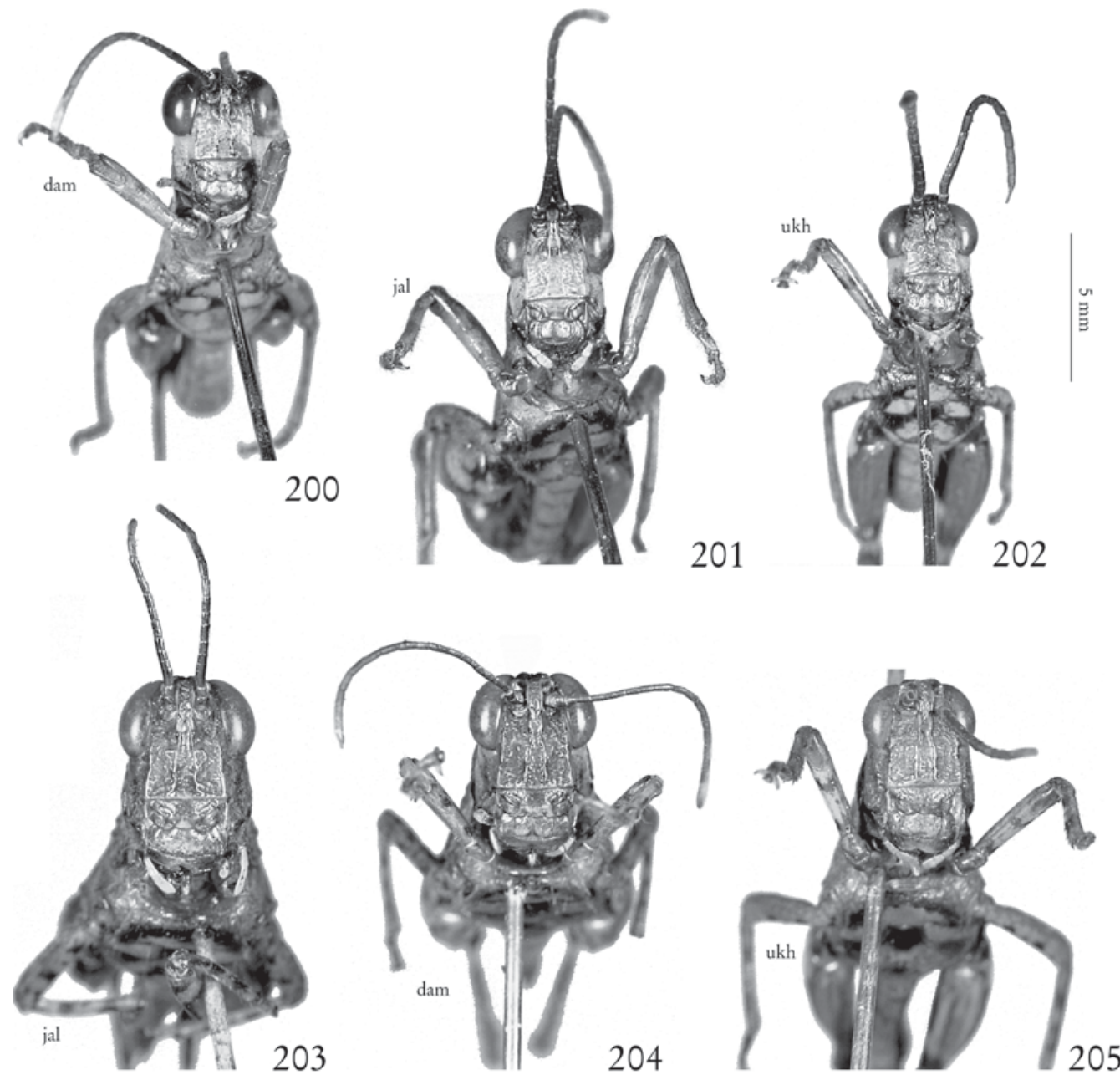

Figs. 200-205. Frons of Apalniacris species from NE India. - 200, A. dampha sp. n. male (holotype); 201, A. jalpaiguri sp. n. male (holotype); 202, A. ukhrul sp. n. male (holotype); 203, A. jalpaiguri sp. n. female (paratype); 204, A. dampha sp. n. female (paratype); 205, A. ukhrul sp. n. female (paratype). 


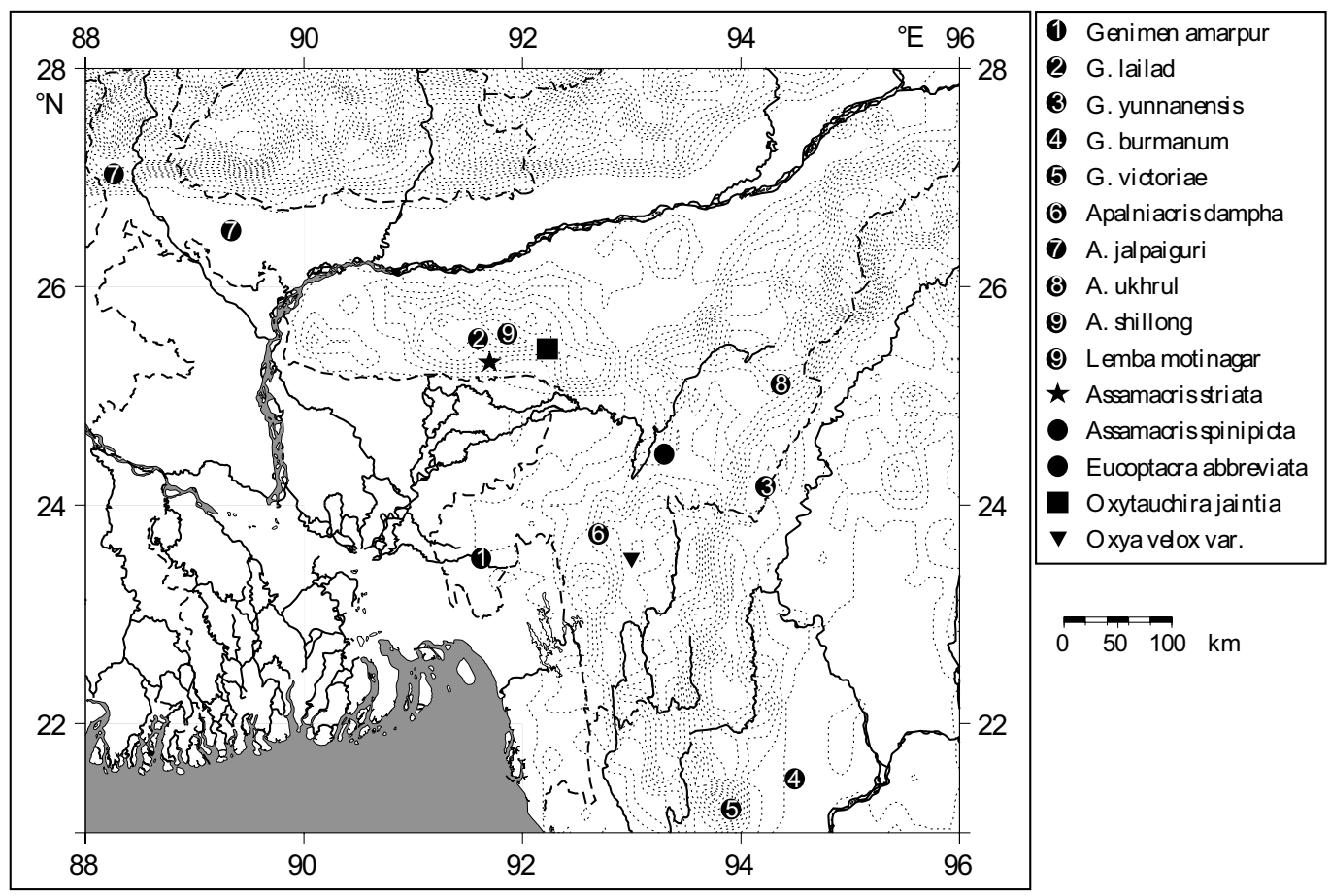

Fig. 206. Localities of the reported Acrididae species in NE India and type localities of some other species. The position of locality 2 is a rough estimate as no geographical coordinates could be traced. (Map outline with OMC http://www.aquarius.geomar.de/, modified). 